\title{
6 Dutch junk news on Reddit and 4chan/pol
}

\author{
Sal Hagen and Emilija Jokubauskaitè
}

\begin{abstract}
This chapter investigates the presence of junk news on Reddit and 4chan's /pol/ subforum, spaces often described as "alternative" owing to their lower user numbers and subcultural ethos compared to the likes of Facebook. We first delineate Dutch spheres within the two spaces over multiple years, finding a rising number of posts within Reddit's Dutch sphere and a stagnant yet non-negligible number of Dutch posters on $4 \mathrm{chan} / \mathrm{pol} /$. We then categorise and analyse what URLs are shared to gauge the presence of junk news domains. We find that Reddit seems fairly resilient against the presence of disinformation or other forms of junk news, save for the appearance of some hyperpartisan sources and incidental malicious users. $4 \mathrm{chan} / \mathrm{pol} / \mathrm{shows}$ a somewhat more problematic situation, returning a larger presence of (foreign) junk news sources.
\end{abstract}

Keywords: Reddit, 4chan/pol/, junk news, alternative media, digital methods

\section{Introduction: The understudied, deep vernacular Web}

Recent debates on online fake news and disinformation have largely been discussed with respect to the social media behemoths in the context of a 'platformized' internet ecosystem (Helmond, 2015), with Facebook, Twitter, Instagram and YouTube in the spotlight. It is not without reason; given their gigantic user bases, open publishing and micro-targeting, they are vulnerable

1 The research team includes Lucie Chateau, Gabriele Colombo, Ognjan Denkovski, Carmen Ferri and Holly Foxton.

Rogers, Richard, and Sabine Niederer (eds), The Politics of Social Media Manipulation. Amsterdam, Amsterdam University Press 2020 DOI: 10.5117/9789463724838_CHo6 
to disinformation campaigns and dubious information, not so unlike the Web itself. Regardless, they do not exist in a vacuum. On the fringes of the Web, yet difficult to characterize as marginal, are pseudonymous or anonymous platforms like Reddit and 4chan. Instead of public-facing 'e-celebs' or otherwise identifiable accounts, these spaces are characterized by 'masked' users with distinctive subcultural styles, vernaculars and iconographies. The pseudonymous and anonymous users on Reddit and 4chan do not only congregate around shared interests or common goals, but also - and in some cases predominantly - around a deep understanding of shared subcultural knowledge and norms. The unconventional and sometimes downright esoteric cultural productions some of these groups create feed into community members' self-imagination as 'underground', 'countercultural', or 'internet native'. 4chan and (parts of) Reddit can be associated with the term 'deep vernacular Web' (Tuters and De Zeeuw, 2019), referring to online discussion forums that lack stable user identities and whose masked participants frequently transgress the boundaries of 'mainstream' conventions, often through an entangled mix of sincere ideology and ironic play.

While Facebook, Twitter, Instagram and YouTube have already been studied in relation to issues of 'fake news', the abovementioned 'virality-oriented subcultures' of the deep vernacular Web are also said to play a 'crucial role in the system' of the circulation of various types of 'junk news' (Venturini, 2019). 4 chan and certain parts of Reddit have indeed been characterized as hotbeds for disinformation (Shiebel, 2017; Collins and Russell, 2018; Lagorio-Shafkin, 2018), trolling campaigns (Phillips, 2015), and conspiracy theories (Marwick and Lewis, 2017; Tuters et al., 2018). Despite their relatively marginal number compared to more mainstream platforms, users of 4 chan and areas of Reddit are considered particularly skilled in 'setting the agenda' of broader news media (Phillips, 2018). In a 2017 report, Marwick and Lewis highlight how an underground current of Internet subcultures associated with 4chan and Reddit 'take advantage of the current media ecosystem to manipulate news frames, set agendas, and propagate ideas' (Phillips, 2018: 1). Later, Phillips builds on this research by exploring how and why the false narratives of these online antagonists were amplified by major U.S. news outlets (2018). As she identifies, journalists were keen on reporting the narratives with false information or dark undertones partly because of a fascination with their bizarre cultural phenomena or simply due to a lack of time required to decipher their problematic code language. The reporting, she argues, 'amplifies' their overall presence. By 2019, there are now well-known by-products of this cycle of the normalization of false content emerging from fringe online spaces. To provide but one example, the 'Pizzagate' conspiracy theory, originating on 4chan, presumed the Clintons 
were maintaining a child sex trafficking ring, which led to media coverage and an actual shooting in a US pizza parlour (Tokmetzis, 2018; Tuters et al., 2018). A related conspiracy theory, 'QAnon', gradually spread from 4chan to Reddit and mainstream news sources (Hagen et al., 2019), even sprouting international support groups including 'QAnon Nederland' (QAnon Netherlands).

The influence of fringe internet subcultures on the news ecosystem has mostly been scrutinized in relation to English-language spheres and U.S. politics. As such, it remains unclear to what extent the propagation of problematic content from the 'deep vernacular Web' affects other news ecosystems such as the Dutch. Such activity already has caught the attention of Dutch media outlets. For example, the QAnon conspiracy was covered by major outlets like RTL Nieuws (2018) and Algemeen Dagblad (Van Huet, 2018), while De Correspondent untangled the related Pizzagate conspiracy in some depth (Tokmetzis, 2018). De Volkskrant discussed Dutch users active in the far-right 'politically incorrect' subforum of $4 \mathrm{chan}$, /pol/, by observing an increasing prevalence of anti-Semitic conspiracies (Kranenberg and Bahara, 2018). In a broader sense, conspiratorial rhetoric native to the deep vernacular Web seems to be normalizing in the Dutch political and media discourse at large. For instance, the concept of 'cultural Marxism' has increasingly appeared in Dutch news media (Van den Bos, 2018). It concerns a theory assuming a Marxist and/ or Jewish network pulling the strings of European institutions - a narrative particularly popular on $4 \mathrm{chan} / \mathrm{pol} /$. Dutch politicians have subsequently flirted with such sweeping theories. For instance, the party Forum voor Democratie tweeted that Mark Rutte was a puppet of the Jewish philanthropist George Soros, ${ }^{2}$ while the party's leader Thierry Baudet supported the most conspiratorial aspects of the 'cultuurmarxisme' debate, tweeting that the European Union is 'a cultural Marxist project aiming to destroy European civilization'. ${ }^{3}$ NOS, the public broadcaster, subsequently published an article framing George Soros as an 'influential meddler with tentacles deep in world politics', ${ }^{4}$ which was later withdrawn after heavy criticism pointing out the

2 The original Dutch tweet by Forum voor Democratie notes: ‘@MinPres [i.e. Mark Rutte] draait er niet eens meer omheen: De belangen van NDO's (lees: Soros) gaan boven het beleid van de democratisch gekozen regering van \#Hongarije. Hoogste tijd dat deze loopjongen van het grootkapitaal nu van het toneel verdwijnt. Reken af met \#Rutte op 20 maart! Stem \#FVD' (@fvdemocratie, 14 Sep. 2018).

3 The original Dutch tweet by Baudet noted: 'Omdat de Europese Unie een cultuurmarxistisch project is dat tot doel heeft de vernietiging van de Europese beschaving' (@thierrybaudet, 19 Aug. 2017).

4 In their original article, NOS used the title 'George Soros: invloedrijke bemoeial met tentakels ver in de wereldpolitiek' and noted: 'De jood Soros steunt organisaties die regeringen openlijk bekritiseren [...]. Dat moet stoppen, zeggen tegenstanders' (Peek 2018). 
framing's commonalities with anti-Semitic rhetoric (Peek, 2018). While direct ties between such mainstream attention and fringe internet platform rhetoric are not to be drawn, each incident in its own right could be situated in the aforementioned dynamics of amplification in a Dutch context.

The falsehoods cooked up on the deep vernacular Web are hard to grasp through the concepts of 'disinformation' or 'fake news', since their 'fakeness' is broader than deliberately coordinated campaigns or clearly false information. Rather, they speak to what Muirhead and Rosenblum (2019) call a 'new conspiracism', whereby sweeping accusations are made independent of evidence or coherent explanations, and complex phenomena are 'explained' through 'conspiracy without theory'. Such conspiracism is said to be dangerous since it delegitimizes the knowledge-making institutions at the foundations of democratic societies (Muirhead and Rosenblum, 2019). Importantly, this conspiracism can be fuelled by or work alongside a mix of foreign interferers, sincere believers and hyperpartisan actors.

To understand these broad range of actors and interests that stimulate the emergence of problematic information, the concept of 'junk news' (or 'pulpnieuws') is more apt. Junk news shifts the focus from clear and coordinated falsehoods towards a broader notion of news crafted to be engaged with and to circulate, which, in turn, stimulates polarizing or 'simple' information that 'saturates public debate' (Venturini, 2019). Junk news thereby forms an umbrella term for conspiracies, hyperpartisan slander, 'ironic' falsehoods, low-effort clickbait articles, as well as deliberate disinformation. The circulation of these types of junk news has a plethora of reasons, but as noted 'tightly-knit communities' (Zannettou, 2017) and 'virality-oriented' subcultures creating and engaging with this highly 'shareable' content are said to be a crucial factor in their effectiveness (Venturini, 2019).

Much has been said about the grassroots production of false narratives within spaces like Reddit and 4chan (Marwick and Lewis, 2017; Phillips, 2018; Tuters et al., 2018; Benkler et al., 2018). However, a more elementary question is usually left untouched: what kinds of news sources do these actors rely on themselves? Zannettou et al. (2017) found that "fringe" communities often succeed in spreading alternative news to mainstream social networks and the greater Web' (1), employing a statistical model (Hawkes process) that indicated that fairly marginal spaces like Reddit's pro-Trump subforum $\mathrm{r} /$ The_Donald and 4chan's /pol/ board are often first to post a URL to alternative news, only later catching attention on Twitter. They furthermore traced which alternative sources were shared on Reddit, 4chan, and Twitter, showing that alternative news was shared more often on $4 \mathrm{chan} / \mathrm{pol} /$ and 
select subreddits than on Twitter, noting the popular use of breitbart.com, rt.com, infowars.com, and sputniknews.com across the three platforms.

What about junk news in a Dutch context? Is there a Dutch alternative 'junk news' network within the deep vernacular web, or do these platforms mostly rely on mainstream sources? If found, how vast is the presence of Dutch junk news in these spaces? In identifying linked-to websites, can signs of coordinated disinformation campaigns be discerned? Or are the types of junk news shared mostly hyperpartisan, clickbait, or some other 'junk' category? These questions are of interest when applied to fringe and 'extreme' spaces like $4 \mathrm{chan} / \mathrm{pol} / \mathrm{but}$ can also aid in positioning more widely used yet still largely 'alternative' spaces, like the largest Dutch subreddit, $r /$ thenetherlands. The research reported here thereby begins with the question, where does Dutch junk news appear (if at all) on Reddit and 4chan/pol/? Subsequently, it asks, what kinds of junk news resonate? It concludes with a brief section on YouTube as a possible alternative news network by following the links to Google's video platform.

\section{Demarcating the Dutch spaces and Dutch junk news in the deep vernacular Web}

\section{Case studies: Reddit and 4chan}

For Dutch cases of virality-oriented subcultures, we focus on Reddit and 4chan/ pol/. Although less known than the likes of Twitter, Facebook, Instagram and YouTube, Reddit is one of the largest discussion sites globally, with Alexa metrics currently showing 234 million unique visitors per month. The platform is divided into different subreddits dedicated to the discussion of specific topics, such as r/tennis or r/politics. Posts on these subreddits can be 'upvoted' or 'downvoted' by users. The higher the post's score (upvotes minus downvotes), the higher it is placed in a ranked list of content and the more visibility it gains. In the comment section underneath every post, 'redditors' discuss, debate, or simply joke around. Reddit's Dutch user base seems to be growing (as is shown below), with the largest Dutch subreddit r/thenetherlands amounting to 236,000 'subscribers' at the time of writing. Its growing popularity makes it an increasingly important object of study in a Dutch context. This is heightened by the fact that Reddit has been identified as a target of multiple Russian disinformation campaigns, with 'at least a hundred' IRA accounts influencing the 2016 U.S. elections and campaigns continuing into late 2018 (Collins and Russel, 2018; Lagorio-Shafkin, 2018). Exploring whether such campaigns have also transpired within Dutch spheres of Reddit is thus part of the objective of this research. 
The second case study is 4 chan, an infamous imageboard where users post anonymously within one of its subforums (called boards) dedicated to different topics like videogames or fitness. 4 chan is ephemeral, meaning posts are deleted from the site after a few days or even hours. It is a visual environment conducive to the production of viral content and generation of junk news (Venturini, 2019). The space's creativity extends beyond the generation of alternative theories, as 4chan is also infamous as the 'birthplace of internet memes', as well as a hotbed for nebulous political movements. The latter include 'Anonymous', the loose 'masked' collective of geeks and hackers infamous for trolling and DDoSing the likes of the Church of Scientology and MasterCard (Coleman, 2014), as well as more recently the 'alt-right', once characterized as an 'amalgam of conspiracy theorists, techno-libertarians, white nationalists, Men's Rights advocates, trolls, anti-feminists, anti-immigration activists, and bored young people' (Marwick and Lewis, 2017:3) but now arguably pertaining to the extreme side of those far-right actors. For this research, we chose to focus squarely on 4chan's politics board, /pol/. This is the most relevant board in relation to the research questions, for it is currently among the most active boards on the website 5 and is a fertile ground for conspiracy theories (Tuters et al., 2018) and alternative news sources (Zannettou, 2017). $4 \mathrm{chan} / \mathrm{pol} /$ is a far-right space, identified as a recruitment zone for neo-Nazis (Wendling, 2018) and connected to various acts of extreme violence (Hankes and Amend, 2018). This partisanship naturally affects the types of news shared on this platform. For balance, other partisan areas of the deep vernacular Web were also considered (e.g., 8chan/leftypol/) but were ultimately found too insignificant in terms of Dutch activity.

\section{Tools and timeframe}

In contrast to mainstream platforms like Facebook and Twitter, data from Reddit and 4chan are rather accessible. For most of the data collection, we used 4CAT (Peeters and Hagen, 2018), a tool developed by the Digital Methods Initiative that captures data from a variety of sources, including $4 \mathrm{chan} / \mathrm{pol} /$ since November 2013. For Reddit, 4CAT makes use of the Pushshift API, which allows access to an archive of nearly all Reddit posts and comments (Baumgartner, 2018).

We chose a timeframe from 1 December 2015 up to 1 June 2019, spanning $41 / 2$ years in total. Whereas most other studies in this volume present

5 At the time of writing, the website 4stats.io, which tracks activity on each 4 chan board, lists /pol/ and /v/ (video games) as the most active boards, with almost $5^{\circ}$ posts per minute and 120 thousand posts per day (taking the last 4 weeks as a benchmark). These numbers are supported by metrics from our own tools (Peeters and Hagen, 2018). 
Figure 6.1 The frontpage of Reddit (retrieved 11 June 2019)

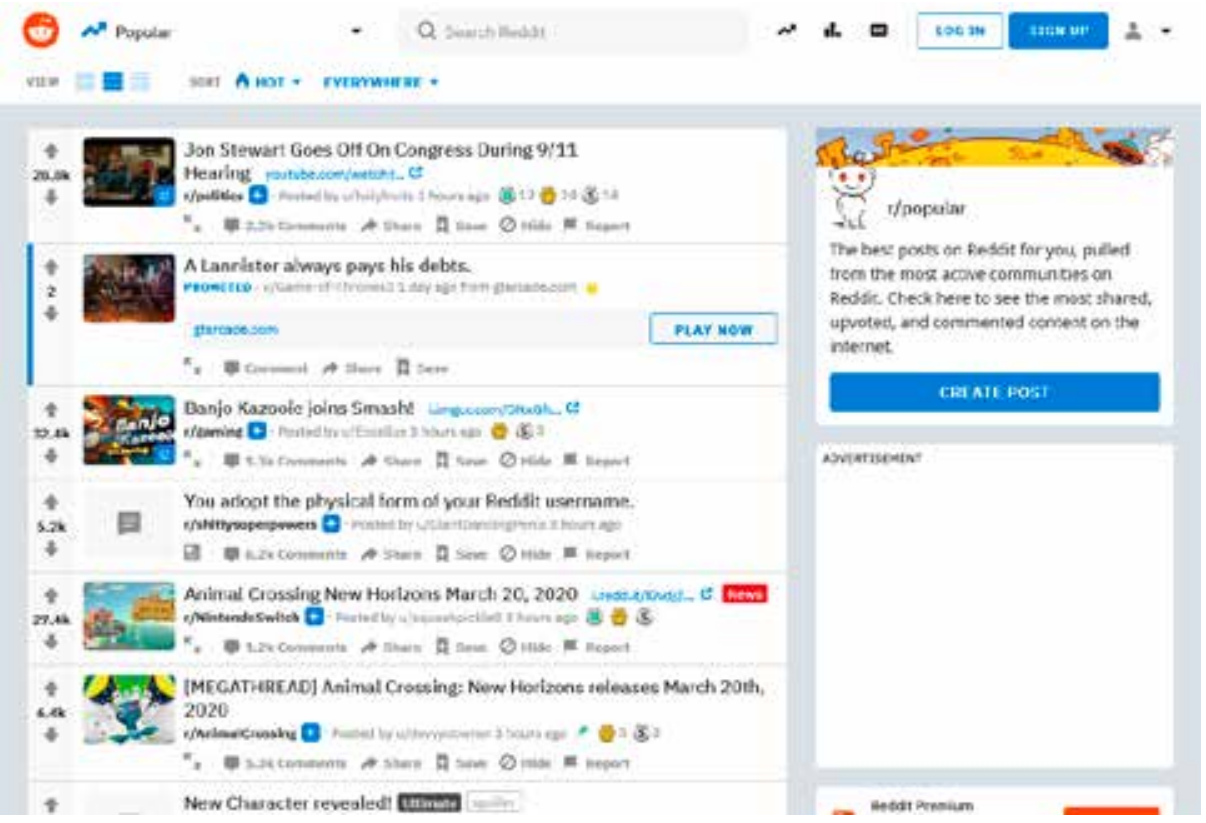

Figure 6.2 The index page of $4 \mathrm{chan} /$ pol/ (retrieved 11 June 2019)

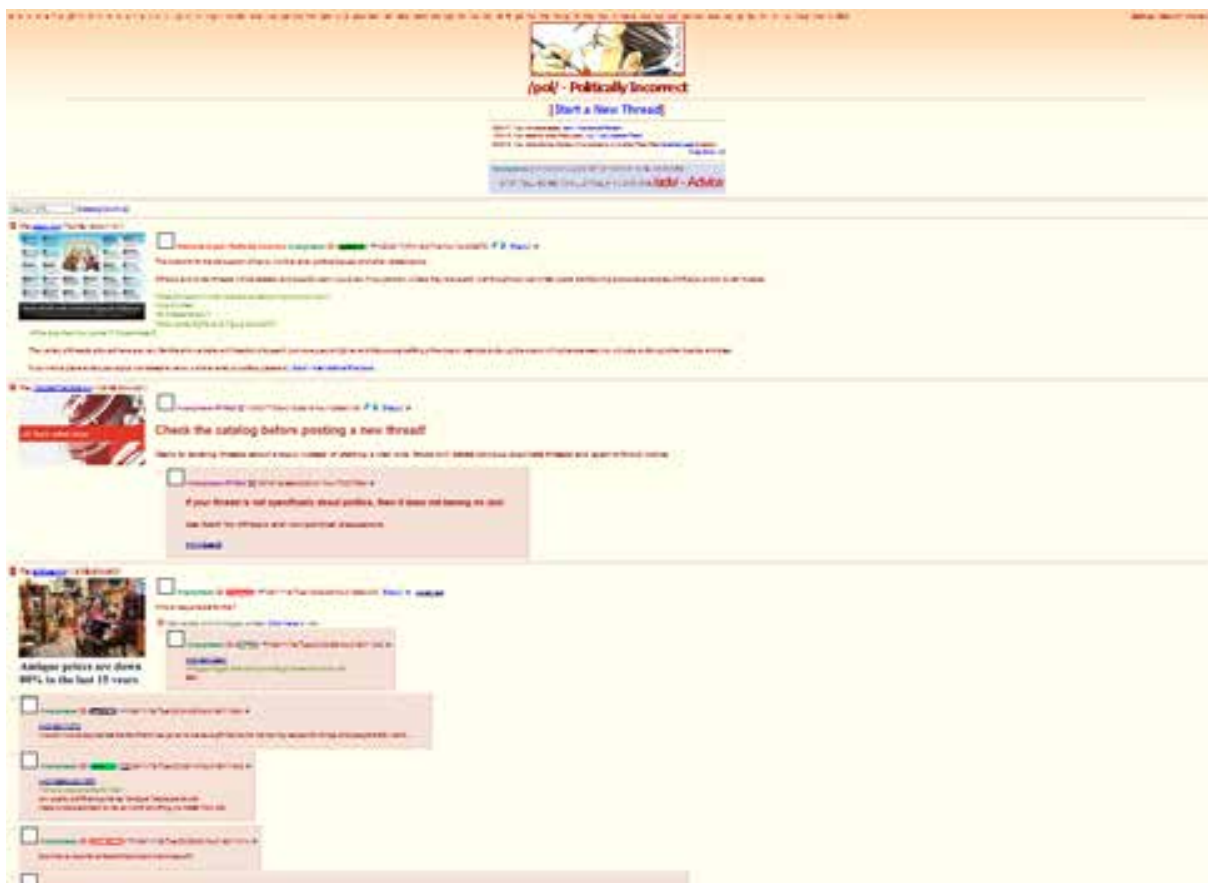


timeframes based on specific events, this long-term timeframe is more suitable here for multiple reasons. Firstly, as we will show, the activity in relation to junk news posting on these platforms was shown to be fairly marginal in comparison to more mainstream social media websites. A larger timeframe thereby aids to arrive at patterns in this relatively small stream of data. Secondly, to the best of our knowledge, it is the first time the presence of questionable Dutch news is researched on these platforms, so it makes sense to start with a high-level perspective on the object of study instead of limiting it to a particular case. Moreover, this timeframe includes a variety of major political events in the Netherlands, including the general elections in 2017 and more recently the provincial and European parliamentary elections in 2019.

\section{Analyses: Haystack to needle and needle to haystack}

As the research focuses on the presence of junk news linked to on Reddit and $4 \mathrm{chan} / \mathrm{pol} /$, it takes URLs as the primary research objects. To provide an overview of the types of news linked to, we decided to focus on domain names (sources) instead of links to individual articles (stories). To identify and categorize domains, we used two related approaches, referred to metaphorically as 'haystack to needle' and 'needle to haystack'. The haystack to needle approach denotes a macro to micro inquiry where all domains posted were categorized in order to subsequently identify the presence of Dutch junk news within this larger pool of data. The needle to haystack does the reverse and starts from an expert list of Dutch junk news domains ${ }^{6}$ and subsequently enquires into when and where these sources appear, and, for Reddit, what kinds of users post them. The next two subsections describe these approaches in more depth.

\section{Haystack to Needle}

The haystack to needle approach moves from a high-level overview to the categorization of particular linked-to domains, specifically by parsing (1) news from non-news, (2) Dutch news from non-Dutch news, and (3) types of junk news (mainstream/junk and types of junk). To do so, a Dutch sphere first had to be defined for Reddit and 4chan/pol/ from which an initial list of domains could be extracted. For Reddit, the full dataset of opening posts

6 The expert list is comprised of an original list by De Hoax-Wijzer, edited to remove inactive sources, with additional sites added through qualitative analysis by University of Amsterdam researchers. 
was filtered for a list of Dutch subreddits (thus excluding comments; the most 'authoritative' and visible URLs are usually in opening posts). The relevant subreddits were compiled from a set of 'related communities' posted by administrators of $r /$ thenetherlands $^{7}$ and supplemented through querying Dutch issues on Reddit. This resulted in a final collection of 182 subreddits (see Appendix 6.1). Not all of these subreddits were equally of interest, but we nonetheless kept the full list considering our bird's-eye approach. On $4 \mathrm{chan} / \mathrm{pol} /$, all posts show a flag icon indicating the location of the IP address of the poster. To identify a Dutch sphere on /pol/, all posts with a country flag of the Netherlands were extracted. It is important to note that this only results in a partial sample of Dutch posters, since users can also choose to display a custom flag (like 'Hippie') instead of one based on geolocation, or they can spoof their IP addresses. In all, the dataset collected consists of over 2 million posts with Dutch country flags, forming a large enough sample to gauge the presence of Dutch junk news using the haystack to needle approach.

Having demarcated Dutch spheres on Reddit and 4chan/pol/, domains from URLs posted were extracted from all posts. For Reddit, this resulted in 3,489 unique domains. To make categorization manageable, only the domains that were posted five times or more were retained. This resulted in a list of 372 domains. Similarly, domain names from the Dutch 4chan/ $\mathrm{pol} /$ posts were extracted using ${ }_{4} \mathrm{CAT}$, yielding 8,048 domains. ${ }^{8}$ To arrive at a comparative sample, we kept the domains that were posted twenty times or more, resulting in $35^{2}$ unique domains.

The two lists were then categorized according to (1) whether the domains were news websites, (2) whether the news websites were in the Dutch language or concerned Dutch affairs, and (3) the category of news websites they would fall in. 'News websites' here refer to a fairly broad selection of websites focusing on the production of news and opinionated columns which contain a section dedicated to timely updates. They include blogs on current affairs, special interest news, and websites of TV news programmes. Thereafter, the news sources were categorized as follows:

- Mainstream: Reporting by 'established' general news outlets with a predominantly neutral tone of voice.

- Other mainstream: All other mainstream news websites concerning special interests, such as business or sports news.

7 See: https://www.reddit.com/r/theNetherlands/wiki/related. Accessed 25 March 2019

8 This is a higher number than for Reddit because for 4 chan, not only the first posts in a thread were kept, but also the replies, matching 4chan's infrastructure of more 'horizontal' conversational threads. 
- Disinformation: Sources deliberately publishing false information, often with harmful intention, and part of a network or campaign.

- Hyperpartisan: Extremely coloured and 'openly ideological' reporting and editorializing from a far end of the political spectrum (Herrman 2016).

- Clickbait: Sources consisting mainly of articles with sensational headlines and gossip, often in the form of cliff-hangers and listicles, with a financial incentive to gain advertising revenue.

- Conspiracy: Sources mainly dedicated to propagating a range of explanations to events behind which are secret plots and multiple actor entanglements.

Three researchers categorized the domains, discussed the debatable cases with other researchers in this volume for higher intercoder reliability, and used external sources like mediabiasfactcheck.com. Mostly, these discussions were held for websites that could be categorized with multiple labels or that fall between hyperpartisan and mainstream such as tendentious ones (Peeters and Rogers, this volume). A caveat to this method is that categorizing websites on a source instead of story level results in stories being labelled, for example, as 'hyperpartisan', even though the categorization would differ on a story-by-story basis. Websites like The Post Online, for instance, contain stories from press agencies as well as tendentious and hyperpartisan ones. Despite this, the rigorous domain categorization did allow preliminary overviews, which is why it was fitting for the 'bird's-eye' perspective of this research. In the haystack to needle approach, we kept and categorized the non-Dutch news sources, since they made up a sizable percentage of posts, especially on 4chan. Considering these are largely Dutch users, it is worth understanding what foreign sites they circulate. To show the different categorizations (news or non-news, Dutch or non-Dutch, types of news), they were visualized in treemap diagrams using the software RAWGraphs (Mauri et al., 2017).

\section{Needle to Haystack}

Next, the needle to haystack approach was used to analyze the prevalence of Dutch junk news in the entirety of Reddit and $4 \mathrm{chan} / \mathrm{pol} /$, now by starting with a list of URLs that were already identified as questionable. This list was constructed by combining an edited list by De Hoax-Wijzer ('Valse Nieuwssites', n.d.) with websites found through engagement analysis by researchers in this volume (see Appendix 6.2). The list refers to Dutch domains known to present news of questionable validity, with an overwhelming partisan 
tone but also occasionally showing traits of conspiracism. The list was coded by the researchers who compiled it and contains the categories hyperpartisan, clickbait, conspiracy, and disinformation. ${ }^{9}$ We fetched all the posts containing these domains with $4 \mathrm{CAT}$, resulting in 1714 posts on Reddit and 443 on $4 \mathrm{chan} / \mathrm{pol} /$.

We then 'scoped' how often junk news appears over time, plotting it as histograms. To compare these junk posts to all of Reddit, Google BigQuery was used. The total number of posts within subreddits where at least one Dutch junk domain appears was fetched to calculate the relative presence of junk news. Additionally, the 'size' of the Dutch Reddit sphere and the entirety of Reddit was retrieved through fetching the total number of posts on Dutch subreddits and on Reddit overall. The data was mapped as circle-pack diagrams with RAWGraphs. For $4 \mathrm{chan} / \mathrm{pol} /$, we used $4 \mathrm{CAT}$ to fetch all posts (both opening posts and replies) mentioning one of the domain names from the expert list in the full timeframe. In order to identify temporal trends, the amount of posts with Dutch junk domains was plotted per month as histograms.

\section{Characterizing junk news propagation on Reddit}

Finally, to characterize the kinds of actors propagating Dutch junk news and the effectiveness of their activities, various metrics were calculated for (further anonymized) junk news posters on Reddit. A similar analysis was impossible for $4 \mathrm{chan} / \mathrm{pol} /$ owing to the imageboard's anonymity and lack of 'repurposable' objects to shine light on the posters. Taking the needle to haystack approach, 4CAT and the Pushshift API were used to retrieve all posts by Reddit accounts who posted a source from the expert list at least twice. The retrieved users were considered 'junk news propagators' for the purposes of this research. The following metrics were calculated for the total corpus as well as for individual users:

- Subreddits most posted often in.

- Average score of all posts as indicated by the Pushshift API. ${ }^{10}$

- Average score of posts referring to Dutch junk news domain as indicated by the Pushshift API.

9 It also has the category tendentious-hyperpartisan, which seeks to capture sources like The Post Online that have stories from press agencies as well as hyperpartisan columns and other contributions that could be described as 'edgy', anti-establishment and against political correctness (Tuters, this volume).

10 These scores might slightly differ from their latest number; Pushshift stores it only once, i.e., upon encountering the post. 
- Most linked-to domains.

- Total posts with domains to Dutch junk domains.

- Percentage of posts linking to Dutch junk domains.

- Total posts by user.

The Reddit users' pseudonyms were (further) anonymized, since not the identity but rather the characteristics of the users is of importance here. The first four metrics in the list above were plotted for the whole corpus in histograms and circle diagrams, while all metrics were also visualized in a matrix for the ten most active Dutch junk news posters, i.e., those who linked to the domains from the expert list most often.

\section{Following and categorizing YouTube links}

YouTube emerged as one of the most popular websites linked to on 'Dutch Reddit' and 'Dutch $4 \mathrm{chan} / \mathrm{pol} /$ '. Since the video platform is often described as offering alternative news consumption, we also followed the links to YouTube videos in all posts in Dutch subreddits and $4 \mathrm{chan} / \mathrm{pol} / \mathrm{posts}$ with a country flag of the Netherlands. Having collected these links, we used 4CAT's 'YouTube metadata' module (in turn using YouTube's API) to retrieve metadata on the videos linked to, such as video title, views, and topics. We then plotted the thumbnails of the $1008^{11}$ videos that were linked to most often on image walls with a custom Python script. To visualize what types of videos these concerned, we plotted YouTube's 'video categories' (selected by the uploaders) on top of the image wall. We finally ranked the most-linked to YouTube channels, derived from the full list of videos linked to on 4 chan and Reddit, to gain a grasp of the type of video content posted.

\section{Scoping Dutch junk news}

This section explores the scope of Dutch junk news on both platforms under study. We do so by showing the volume of posts linking to one of the URLs in the expert list (i.e., the needle to haystack approach). These are then compared to the overall volume of (Dutch) posts on Reddit and $4 \mathrm{chan} / \mathrm{pol} /$.

11 We settled on the peculiar number of 1008 since it would make the image wall adhere to the common 18:9 screen aspect ratio. 
Figure 6.3 Total amount of posts and comments on one of the Dutch subreddits (see Appendix 6.1)

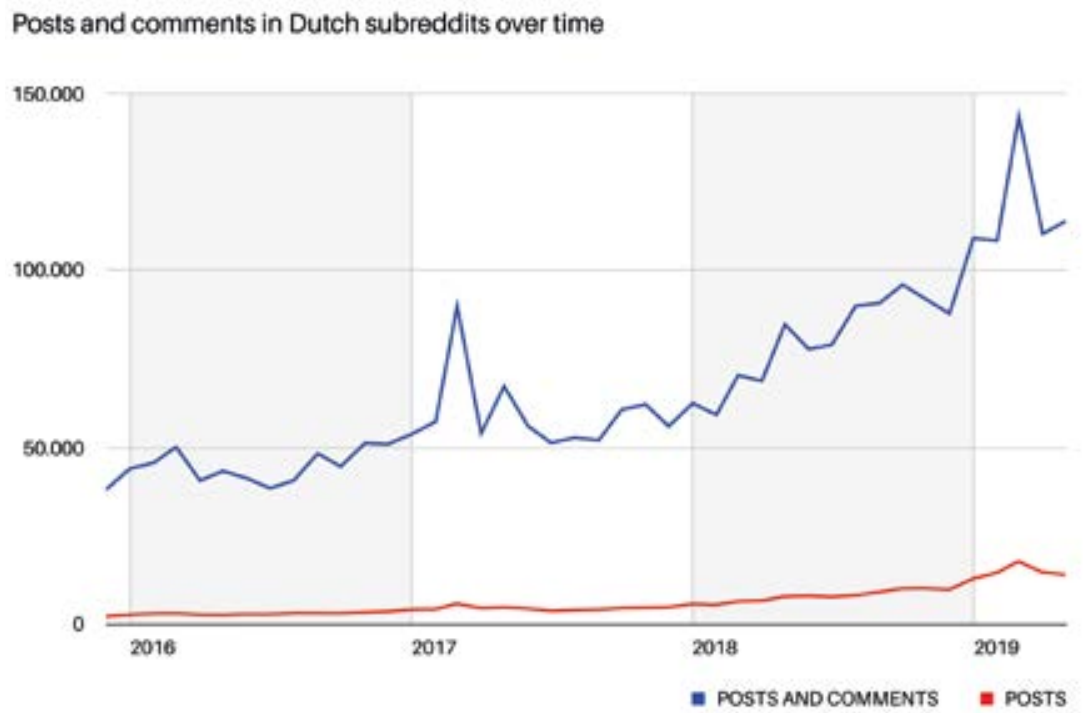

Data source: 4CAT and Pushshift; timeframe: 1-Dec-2015 to 1-Jun-2019; line graph

\section{Scoping junk news on Reddit}

First, as a way to ground the corpus, Figure 6.3 shows the total amount of posts made on one of the Dutch subreddits (Appendix 6.1). Just like activity on Reddit in general, Dutch activity is increasing: in December 2015 there were just over 2,00o posts and comments per month, whereas in January 2019 this number had grown to 14,000 and seems to be rising.

Does this increase in activity also mean an increase in Dutch junk news linked to on Dutch subreddits? As is evident in Figure 6.4, the amount of posts linking to one of the domains from the expert list started at a maximum of just eighteen instances in 2016. Two subsequent spikes can be observed. The first one, in April to July 2017, speak to the 'spammy' nature of some areas of Reddit, since one user frequently posted a Dutch junk news domain (ninefornews.nl) to an English subreddit. The second spike is more varied, however, showing a range of websites like boinnk.nl, worldunity.me, and ninefornews.nl. Upon closer inspection, these were again posted by a single account, mrthirdeye, the closest one will find to a 'fake news troll', though its posts received little to no engagement (discussed in more detail in section 4). The subsequent dip in November 
Figure 6.4 Frequency of posts linking to Dutch junk news domains on Reddit

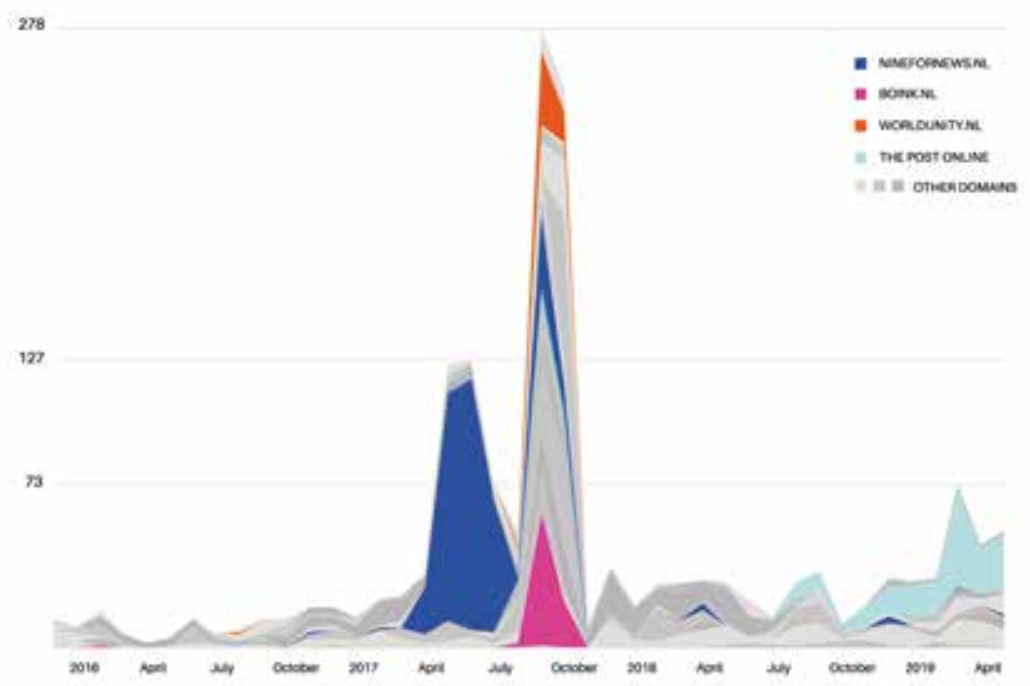

Data source: Google BigQuery; timeframe: 1-Dec-2015 to 1-Jun-2019; stream graph

can be attributed to a content policy change in 2017, possibly leading to the banning of this malicious account (Alexander 2017). In subsequent months, junk news sharing increased somewhat compared to 2016 but remained fairly consistent with around fifty instances per month. An increase of posts linking to (at the time) a tendentious-hyperpartisan website, The Post Online, can be seen in 2019, although no significant spikes during the 2019 Dutch provincial elections and 2019 European elections can be discerned. In perspective, these numbers do not seem extremely troubling, especially since most posts link to hyperpartisan sources instead of outright disinformation (see section 3 ), and furthermore do not receive a lot of engagement (see section 4).

To further put the scope of Dutch junk news on Reddit in perspective, Figures 6.5 to 6.8 contain circle pack diagrams that show its amount compared to the entirety of Reddit, as measured in terms of posting activity (excluding comments). Figure 6.5 shows the size of all subreddits where a link to a Dutch junk news source was shared at least once. The Dutch subreddits are tiny in comparison to non-Dutch subreddits (Figure 6.5), given the dominance of English-language subreddits on the site. There are a few occasions when Dutch junk news was shared on very large subreddits, such as r/viral, r/news, and r/worldnews, as well as the infamous pro-Trump subreddit, The_Donald. Notably, however, in the Dutch subreddits, the proportion of junk news is 


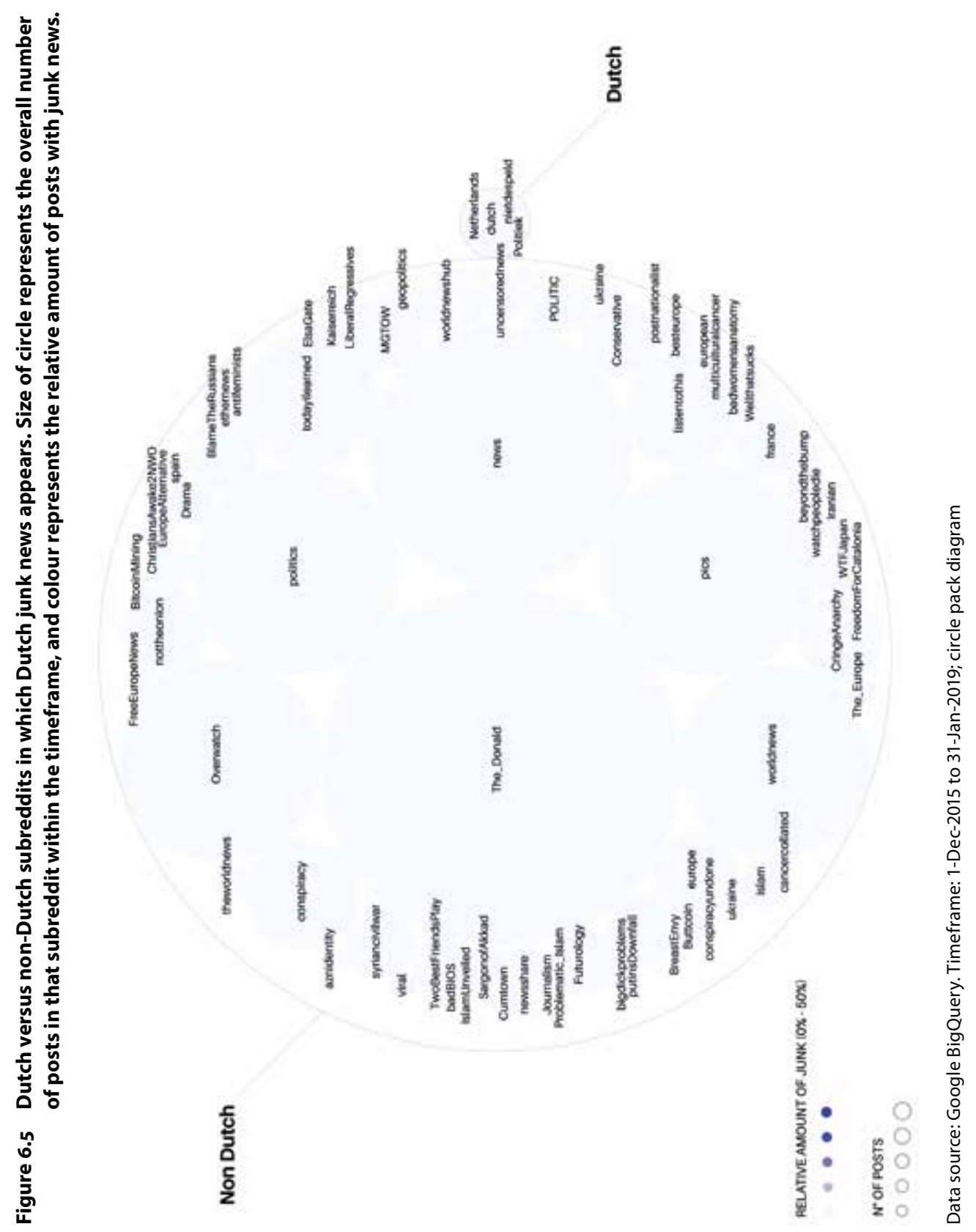




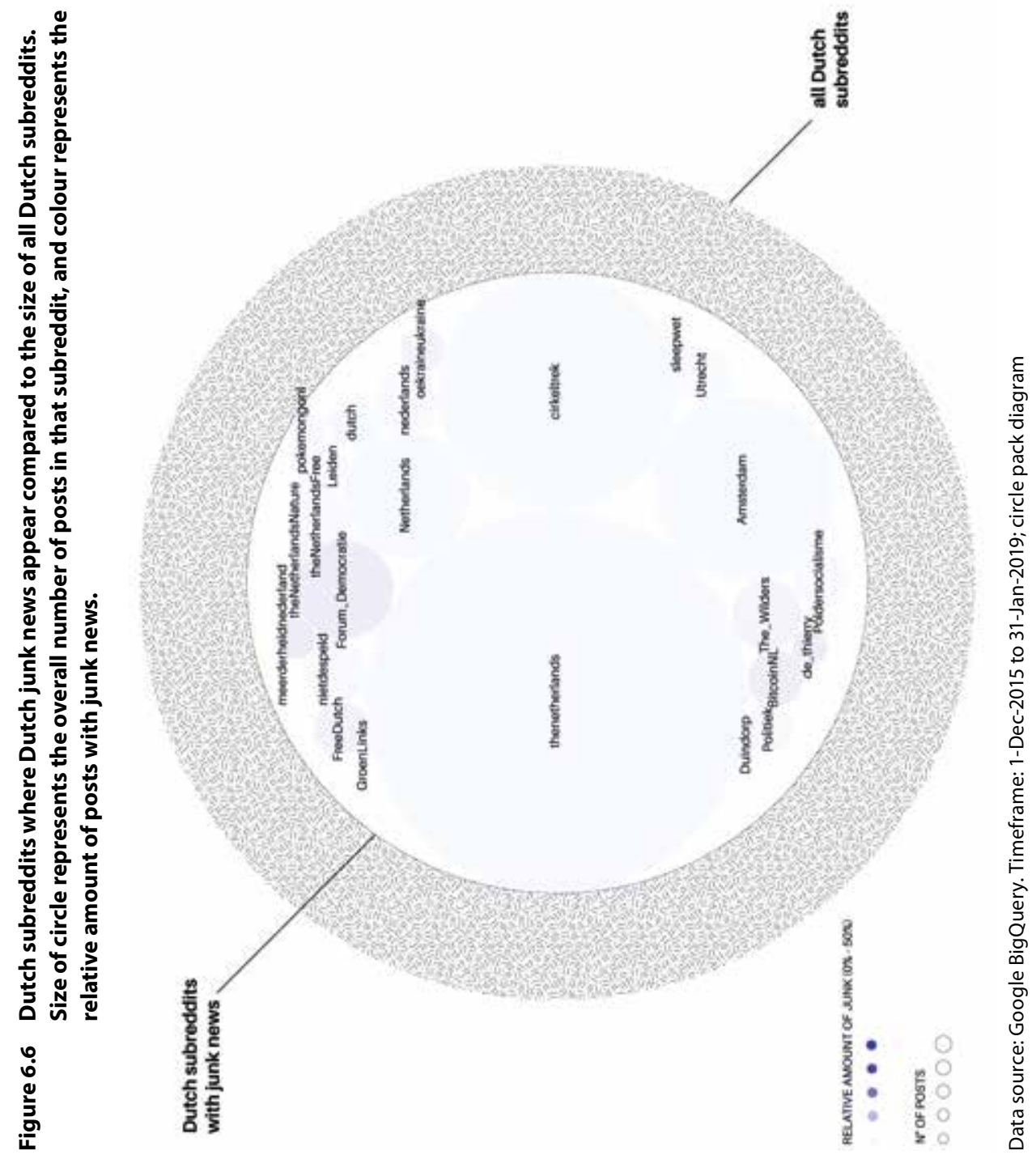


Figures 6.7 and 6.8 All Dutch and non-Dutch subreddits where Dutch junk news appear compared to the size of all of Reddit. Size of circle represents the overall number of posts in that subreddit, and colour represents the relative amount of posts with junk news.
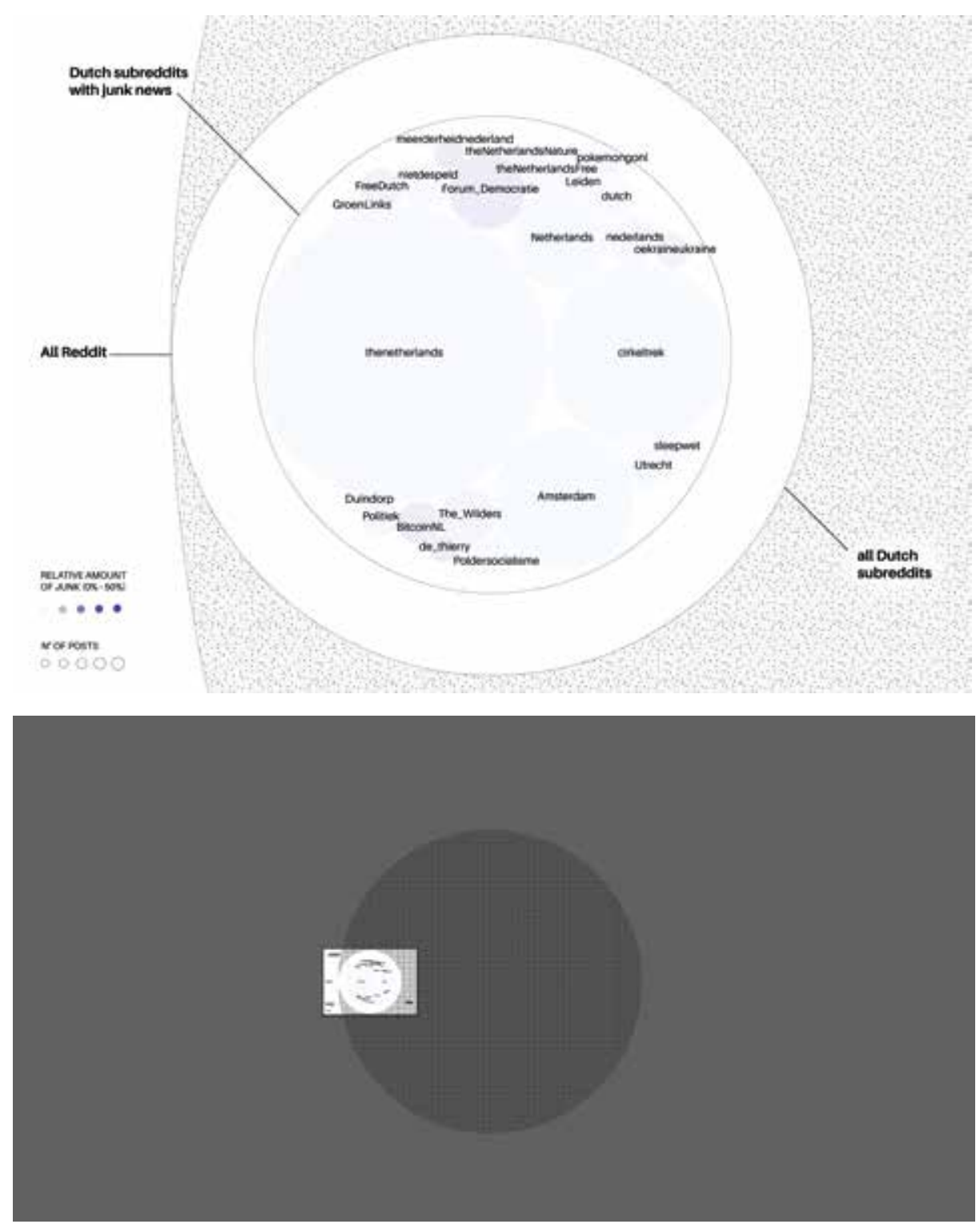

Data source: Google BigQuery. Timeframe: 1-Dec-2015 to 31-Jan-2019; circle pack diagram 
very low as well. As will be touched on, only occasionally does a subreddit have over $5 \%$ of its posts linking to Dutch junk news. For the majority of subreddits, this figure is less than $1 \%$.

When zooming in on Dutch subreddits (Figure 6.6), a clearer variation in the volume of junk news is observable. For the subreddits where these sources appear, they are still in small amounts, with the highest percentages appearing in r/Forum_Democratie ( $5,37 \%$ of all posts), r/meerderheidnederland $(5,67 \%), r / d e \_t h i e r r y(4,93 \%), r / D u i n d o r p(13 \%), r / T h e \_W i l d e r s ~(1,97 \%)$, and $\mathrm{r} /$ FreeDutch $(3,04 \%)$. Most of these subreddits are related to right-wing political parties, ideologies or politicians, such as Geert Wilders or Thierry Baudet. These subreddits appear mostly because of the frequent posting of links to hyperpartisan websites such as De Dagelijkse Standaard.

When compared to the overall Dutch sphere on Reddit (Figure 6.6), quite a large area of the Dutch subreddits has at least some presence of junk news from the expert list. Still, the largest and most mainstream Dutch subreddits ( $\mathrm{r} /$ thenetherlands, $\mathrm{r} /$ cirkeltrek, $\mathrm{r} /$ Amsterdam) contain a negligible amount. Dutch junk news can most notably be seen within already polarized or partisan spaces, such as the right-wing subreddits listed above. Larger and less partisan subreddits like $r$ /thenetherlands seem fairly immune, likely because of a different user base and content moderation.

Lastly, Figures 6.7 and 6.8 provide a zoomed-out visualization of the relative amount of Dutch junk news in the entirety of posts on Reddit. While some Dutch junk news appears in a number of both Dutch and non-Dutch subreddits, it pales in comparison to the total number of posts in other subreddits in the research timeframe. Moreover, even though some Dutch junk news appears on a number of large international subreddits (in turn, making the sphere appear large), the relative number of appearances of Dutch junk news in those subreddits is close to zero. Concluding, then, in terms of frequency, links to questionable Dutch-language news sources on Reddit is a small issue outside of a few partisan subreddits.

\section{Scoping junk news on $4 \mathrm{chan} / \mathrm{pol} /$}

4chan's infrastructure allows less of a comparative approach than that of Reddit, but some metrics can shine light on the relative appearance of Dutch junk news on /pol/. First, to scope the Dutch sphere, the amount of posts with the country flag of the Netherlands is fairly stagnant since late 2015 (Figure 6.9). Each month, around 40,00o 'Dutch flagged' posts are made. The amount increased in March 2017, owing to the Dutch general elections. While these numbers are lower in comparison to Dutch users on 
Figure 6.9 Line graph of posts with Dutch country flags on 4chan/pol/

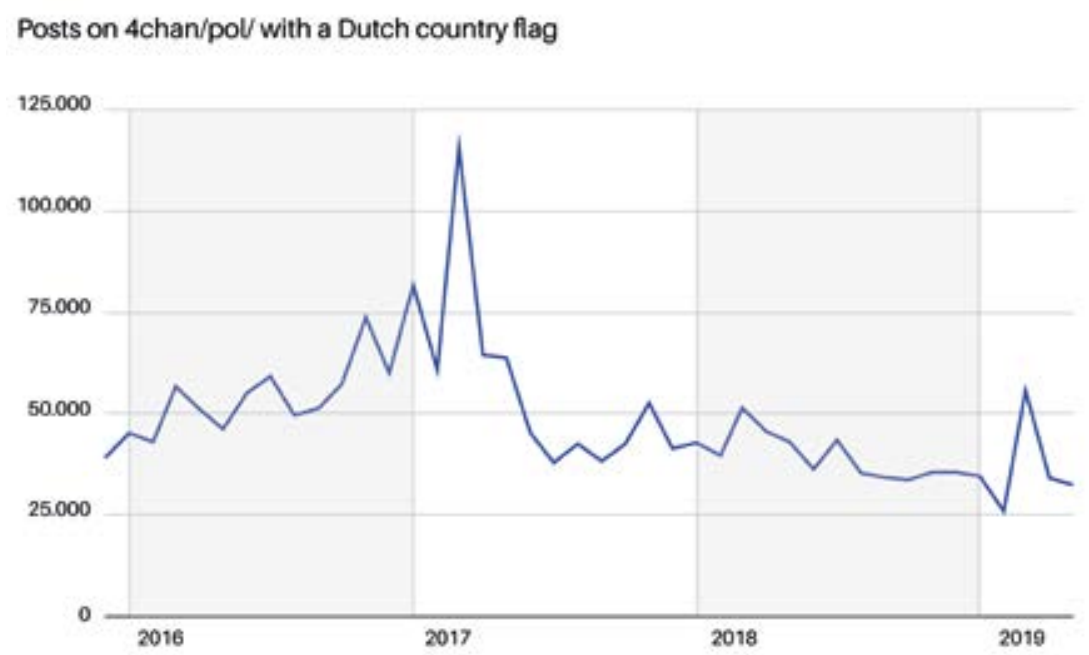

Data source: 4CAT; timeframe: 1-Dec-2015 to 01-Jun-2019; line graph

mainstream platforms like Facebook, they are at times comparable to Reddit, and a non-negligible number - a fairly significant insight considering the extreme political ideas present on /pol/. It is impossible to tell how many individual people these numbers of posts denote, however.

Despite the frequent Dutch posts on /pol/, the amount of posts linking to Dutch junk news is quite low (Figure 6.10). Links to Dutch junk news domains appear only around ten times per month. One significant spike occurs in March 2017, caused by links mostly to The Post Online and De Dagelijkse Standaard, again concerning the general election on March 15 . Interestingly, a similar spike associated with the elections is absent from Reddit. Afterwards, however, the amount of posts linking to Dutch junk news drops, remaining low for both the 2019 Dutch provincial elections and the 2019 European elections. Considering the total amount of posts by Dutch /pol/ users (averaging around 40,00o posts per month), the amount of references to junk news URLs should be considered negligible. This should not be equated with a lack of problematic news content, however, as is discussed below.

\section{Categories of Dutch junk news}

How sizable of a role do online news media play within $4 \mathrm{chan} / \mathrm{pol} /$ and Reddit? What types of domains are linked to when categorizing news domains 
Figure 6.10 Frequency of posts linking to Dutch junk news domains on 4chan/pol/

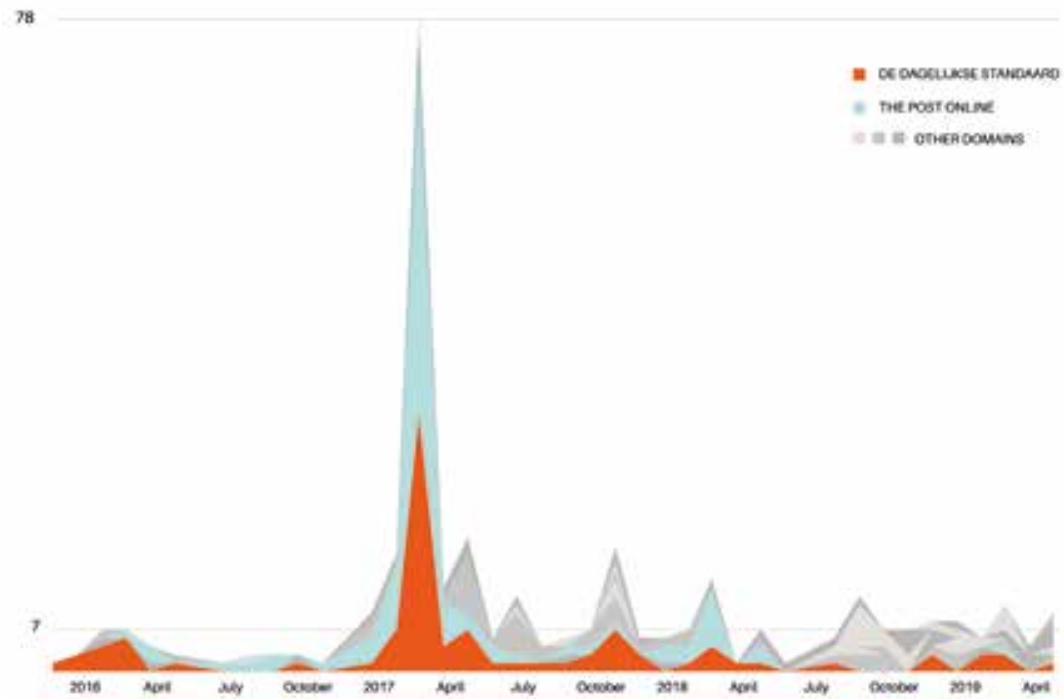

Data source: 4CAT; timeframe: 1-Dec-2015 to 01-Jun-2019; streamgraph

posted in these forums? What types of junk news can we discern? This section uses the haystack to needle approach to walk through a number of tree maps, each showing a different categorization of the most-linked to domains. First, the proportion of news websites is compared to non-news domains. Afterwards, the news websites are sorted by Dutch or non-Dutch. Finally, the categories of these news sources are outlined and discussed (mainstream, hyperpartisan, disinformation, etc.).

Firstly, Figures 6.11 and 6.12 show which domains from the most-posted domain sample are categorized as 'news'. For Reddit (Figure 6.11), 21,6\% of all posts on Dutch subreddits refer to 'news' websites. Notably, tweedekamer.nl appears 15,694 times, caused by the bot u/kamerstukken-bot posting parliamentary texts to the subreddit $\mathrm{r} /$ kamerstukken. Removing this bot increases the news proportion to $50 \%$ - quite a considerable number. Other non-news websites include reddit.com itself, often used to host images and text, and youtube.com and youtu.be, appearing $95^{1}$ times cumulatively.

$4 \mathrm{chan} / \mathrm{pol} / \mathrm{paints}$ quite a different news/non-news picture. At $16.6 \%$ the proportion of links to news websites is lower than Reddit's 50\%. After twitter. com and en.wikipedia.org, a staggering 50\% of URLs point to YouTube. Considering this major presence of Google's video service, it is further scrutinized as an alternative news sphere in section five. 


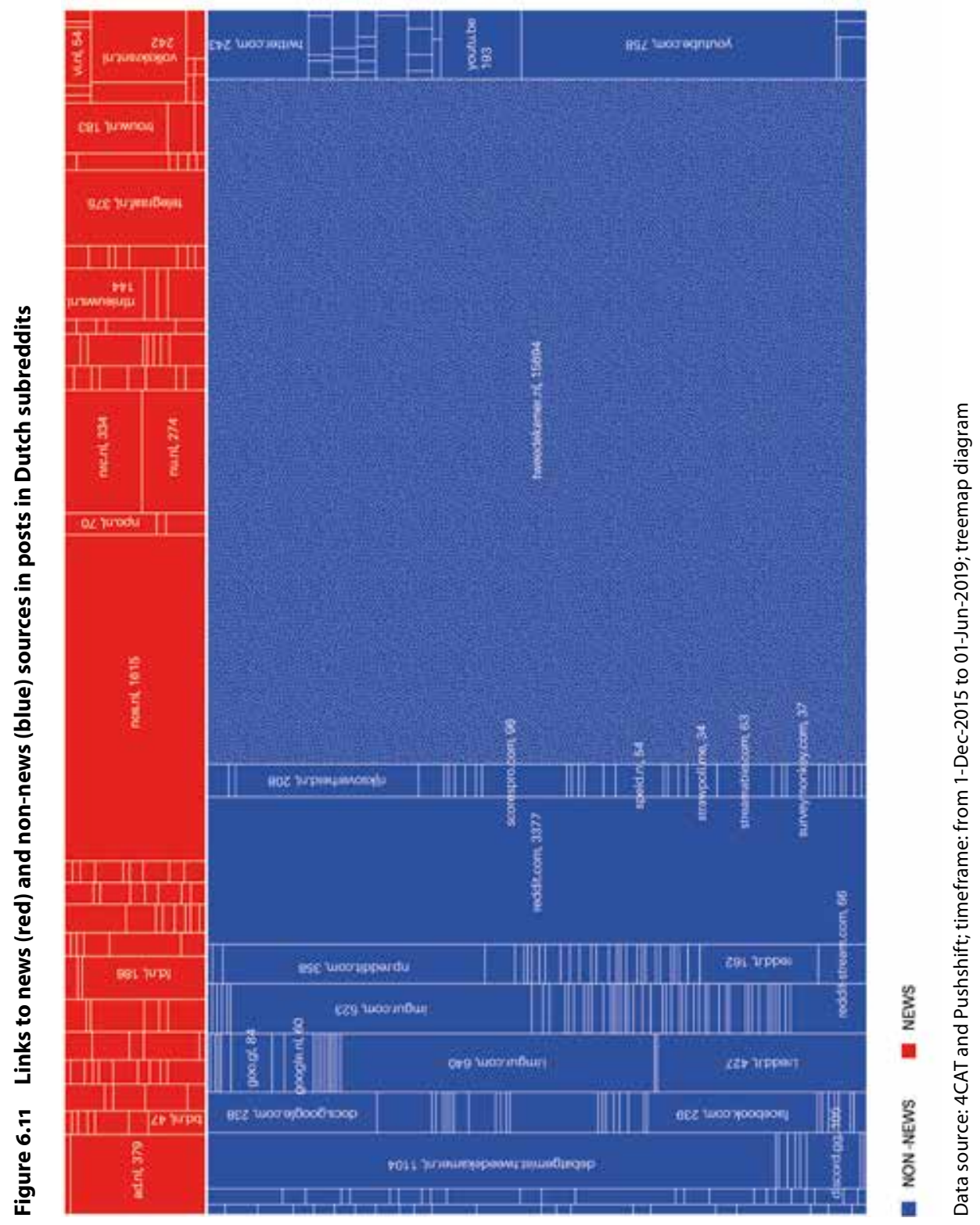




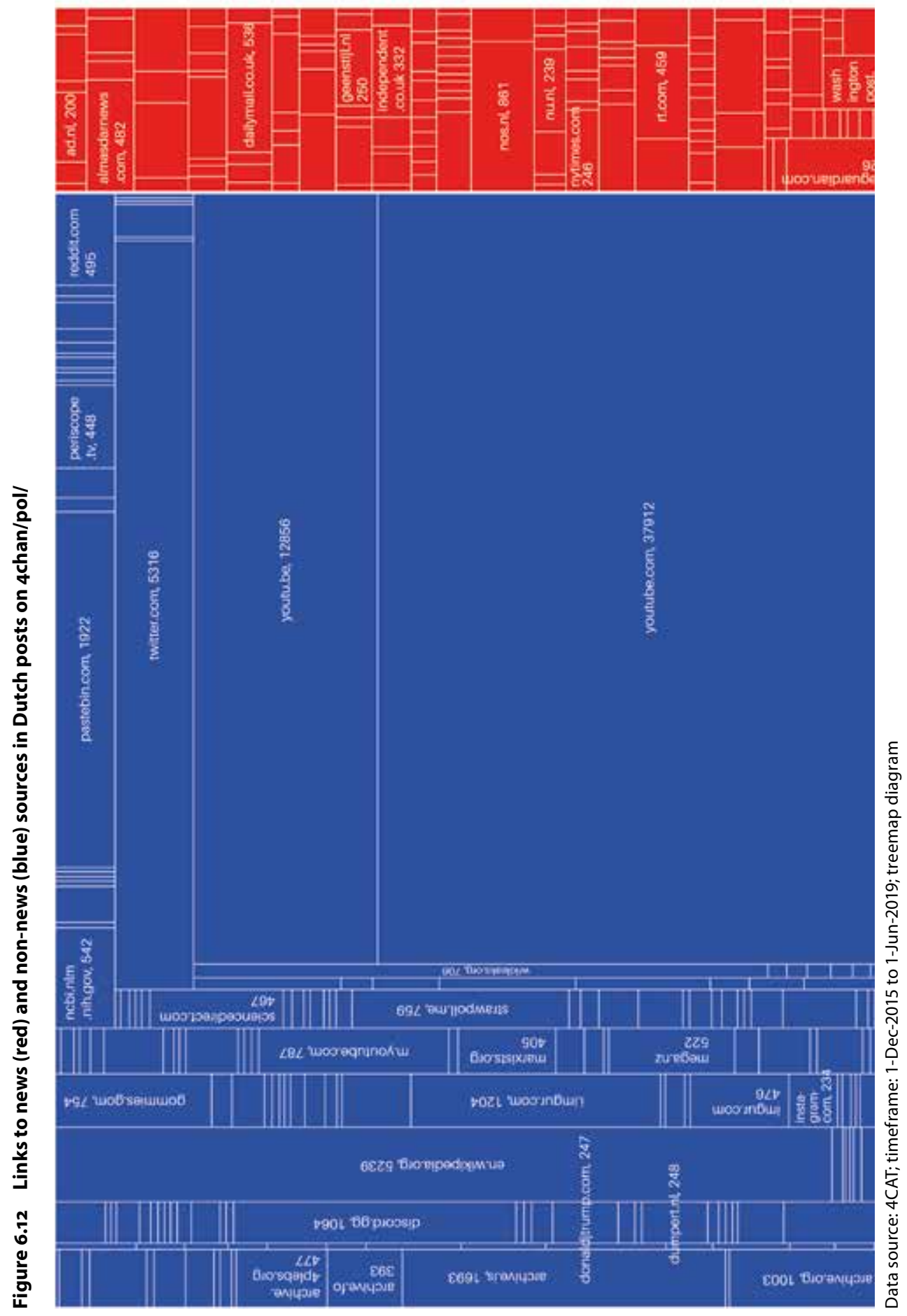




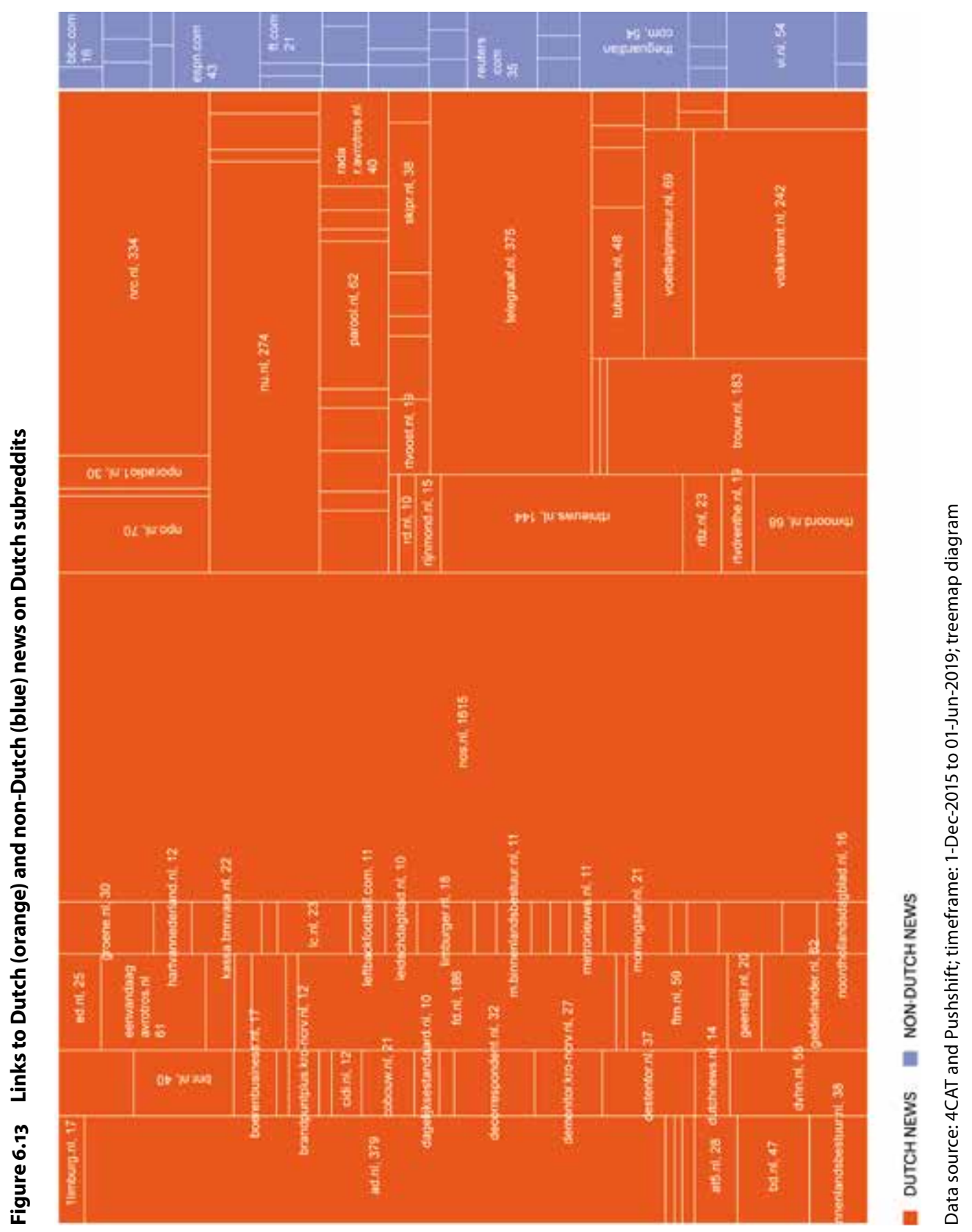




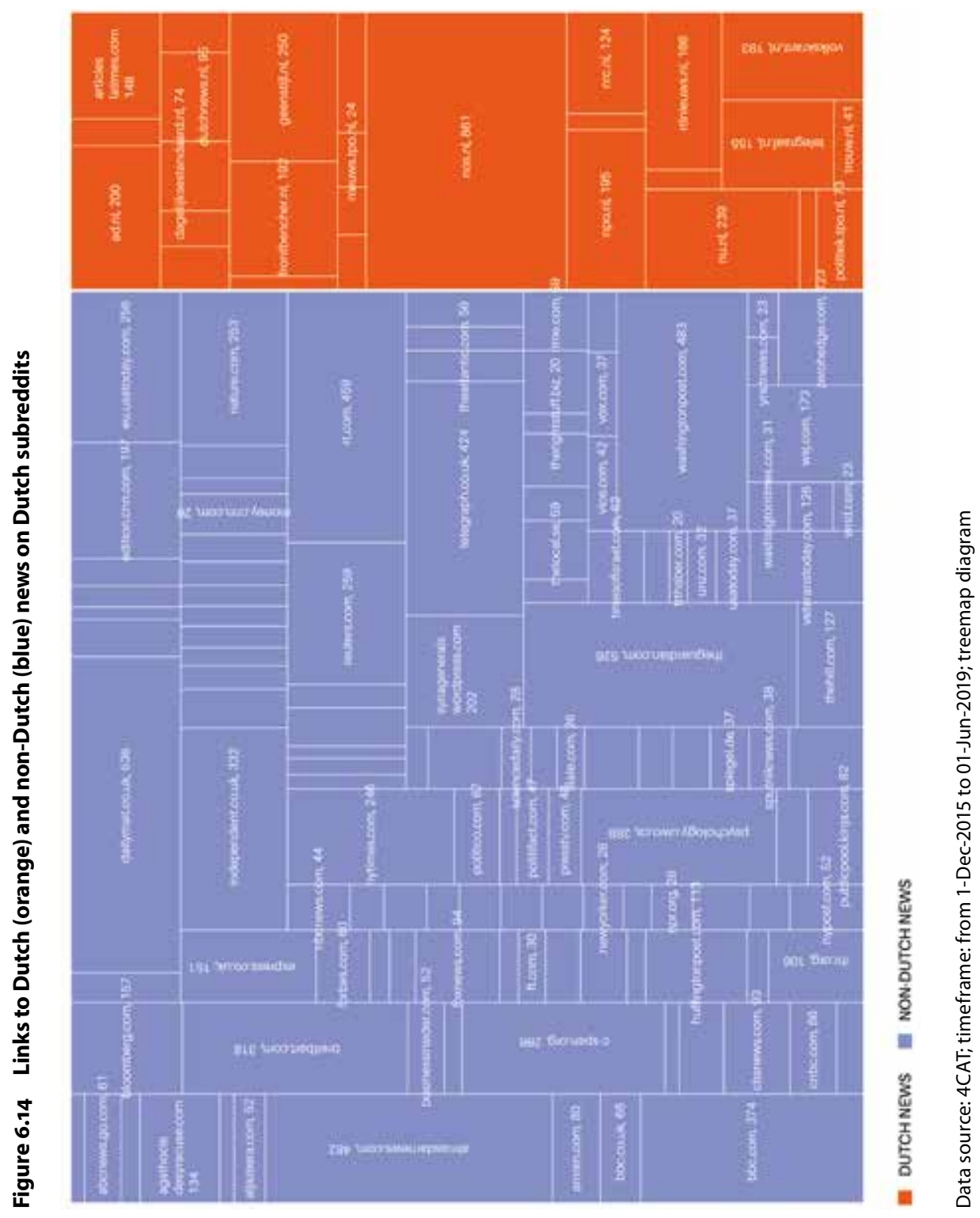




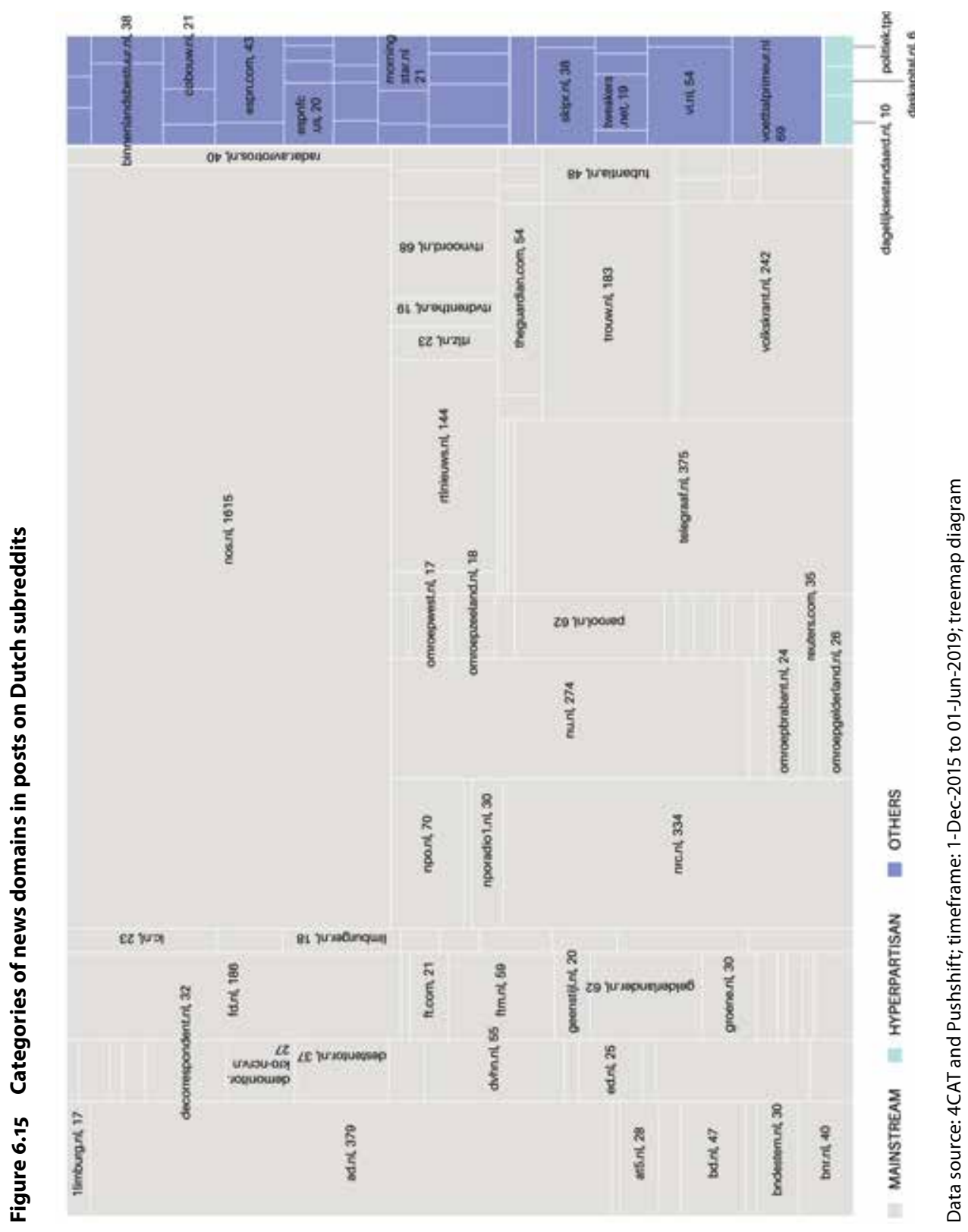




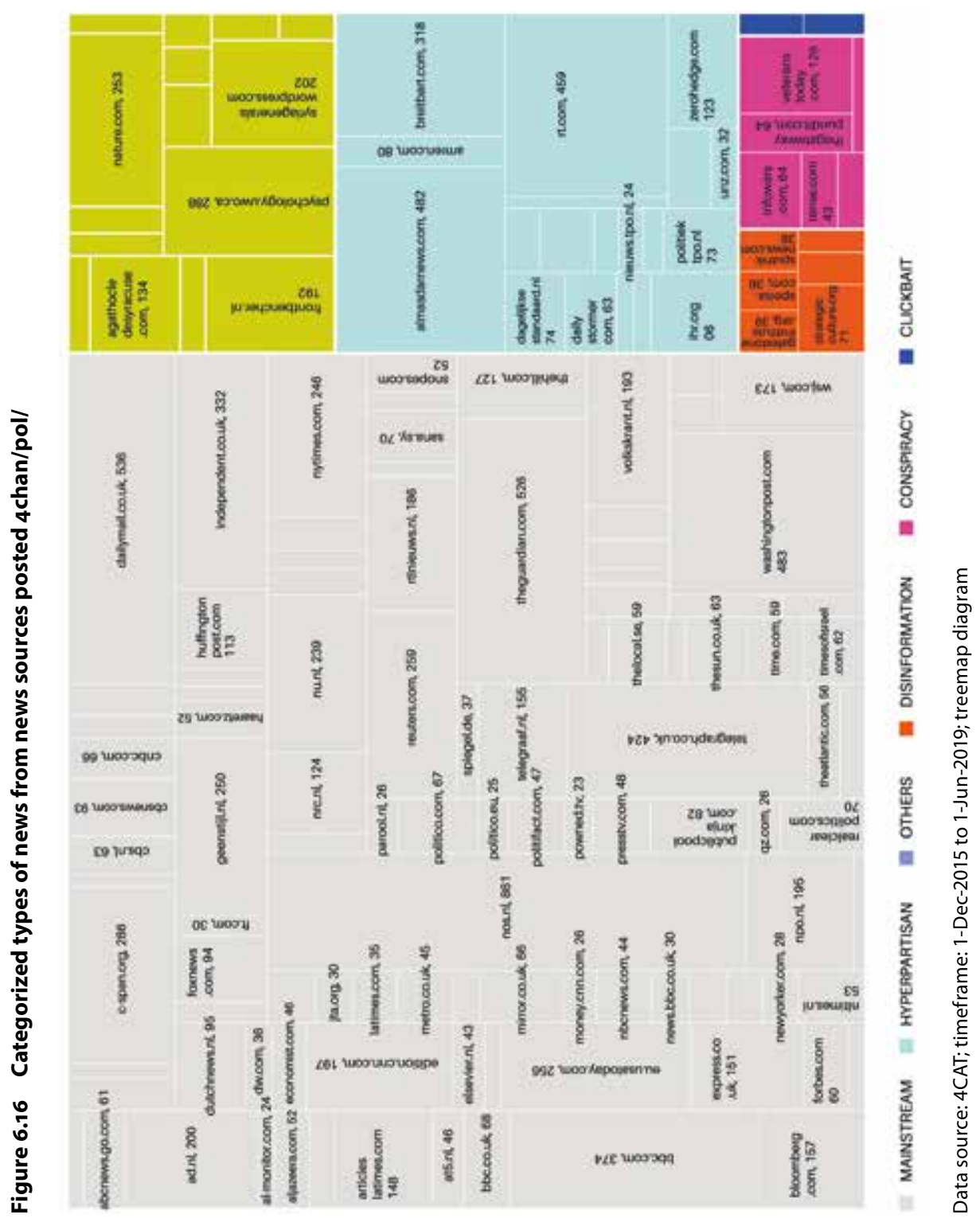


Figures 6.13 and 6.14 show the news domains on Reddit and $4 \mathrm{chan} / \mathrm{pol} /$, respectively, according to their origin (Dutch or non-Dutch). On Reddit, the domains shared on Dutch subreddits are almost exclusively of Dutch origin. This is likely due to content moderation in these spaces, requiring posts to be specifically about the Netherlands (e.g. on $\mathrm{r} /$ thenetherlands). The news sources on $4 \mathrm{chan} / \mathrm{pol} /$ (Figure 6.4), on the other hand, are predominantly from Anglophone sources, such as The Daily Mail, The Guardian, $B B C$, and Reuters. This is fairly unsurprising considering $4 \mathrm{chan} / \mathrm{pol} /$ 's designation as an English language space, unlike the Dutch subreddits. Still, it is worth noting that Dutch users on $4 \mathrm{chan} / \mathrm{pol} /$ are mostly concerned with English sources and are thus more internationally oriented in terms of news propagation than users on Dutch subreddits. This also implies foreign news sources might significantly influence their news consumption. As shown below, English junk news is indeed posted by these Dutch 'anons'.

Next, we explore the types of news sources, and if 'junky', how they can be categorized. Figures 15 and 16 show the categorization of the shared news domains as mainstream, other (mainstream), conspiracy, disinformation, hyperpartisan, and clickbait, as defined in section 1.3.1. As is evident in the visualizations, mainstream or special interest (other mainstream) sources make up the largest share of URLs posted on both platforms: $99,6 \%$ for Reddit and $81 \%$ for $4 \mathrm{chan} / \mathrm{pol} /$. Despite the frequent characterization of pseudonymous spheres like Reddit as 'alternative', these results are thus somewhat counterintuitive since mainstream sources make up the dominant proportion links shared. On both sites, NOS.nl is the most linked-to news source, meaning the established source is highly relevant. For Reddit especially, the lack of problematic content in Dutch spaces is remarkable, as in these most-posted domains almost no websites from the expert list can be found, save for a few instances of dagelijksestandaard.nl and tpo. $\mathrm{nl}$. Indeed, the platform and Dutch users show they seem to be inoculated against 'pulpnieuws'.

Dutch-flagged posts on 4chan/pol/ show a more problematic, hyperpartisan nature. Here, $21 \%$ of top news domains are 'junk', with hyperpartisan sources making up most of these. Some of these are foreign state-influenced and/or hyperpartisan, such as rt.com and breitbart.com, and others are outright extremist, like the neo-Nazi website, The Daily Stormer. As alluded to above, Dutch junk news seems to play less of a role here. A few sporadic instances of far-right disinformation appeared in the Dutch posts (shown in orange), all originating outside of the Netherlands. These include links to sputniknews.com, the large Russian news website that has been known to propagate disinformation (MacFarquhar, 2016; EUvsDisinfo, 2017), as well 
as two far-right websites that post a large amount of Islamophobic stories, Speisa.com and the Gatestone Institute. In posts linking to Russian sources, like rt.com and sputniknews.com, the top URLs are usually referring to refugee slander, particularly in Sweden (see Appendix 6.4). It is impossible to tell who posted these links considering 4chan's built-in anonymity, but it could potentially point to foreign interference.

\section{Characteristics of Dutch junk news propagation on Reddit}

What are the characteristics of online actors who share Dutch junk news? And are their actions effective? While these questions are nearly impossible to answer for 4chan, considering its anonymity, Reddit does afford 'natively digital' (Rogers, 2013) objects to explore the characteristics and effectiveness of junk news propagators. This section will therefore discuss a range of metrics and lists concerning Dutch junk news on Reddit.

298 Reddit accounts were found within the timeframe that linked to domains from the expert list of Dutch junk news domains. Out of those, 193 accounts only posted a Dutch junk news URL once. Only sixteen accounts did so ten times or more, meaning there is a long tail of occasional junk news posters. When these junk news sources are linked to, they furthermore receive a lower score on average than other posts these propagators make (Figure 6.17). To reiterate, Reddit scores are created by users' 'upvoting' or 'downvoting' a post, with a high score meaning a post will move to a higher position on a subreddit, thus receiving more visibility. As can be seen in Figure 6.17, posts to non-junk news by these propagators outperform posts linking to one of the sites in the expert lists, with the propagators' mean score being 9.8 and the mean for their posts linking to a Dutch junk source being 5.6. This is mostly caused by automated, 'spammy' posts. The median for each of these is 1 and overall, 1.24 of the 1.72 of junk news posts have a score of 1 or less $(72 \%)$, meaning the Dutch junk news posts receive little visibility and approval on average.

These low average scores do not mean that junk news stories are totally void of success, however. 33 of the 1,761 posts received a score of $5^{0}$ or more. Reddit's infrastructure stimulates a snowball effect of 'rich get richer' posts, and some of these even scored higher than 1,00o. Zooming in on a URL instead of a domain level, it shows that most of these stories are hyperpartisan of tone. Table 6.1 shows the top three highest-scoring posts on Reddit linking to a domain from the expert list. All three best-performing spots are 'junky' and Islamophobic in tone. The first concerns a story by De Dagelijkse Standaard on rape and refugees. The second and third are both linking to 
Figure 6.17 Mean Reddit posts scores by Dutch junk news propagators (users who posted a link to a Dutch junk news domain at least twice) as reported by Pushshift API

\section{Mean post scores for Dutch junk news propagators on Reddit}

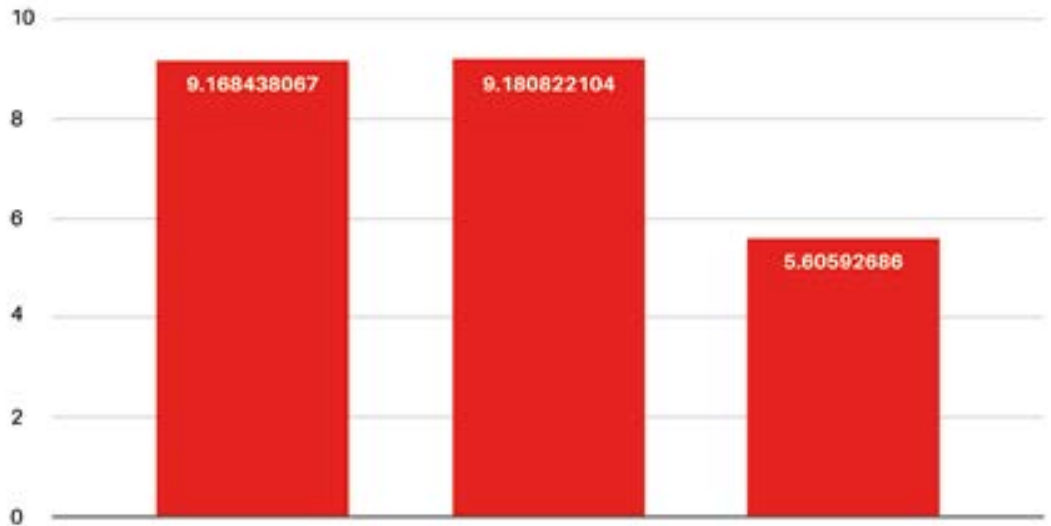

MEAN SCORE OVERALLL MEAN SCORE FOR NON-JUNK MEAN SCORE FOR JUNK

Data source: 4CAT and Pushshift; timeframe: 1-Dec-2015 to 01-Jun-2019; bar graph

Table 6.1 The top 3 best performing posts linking to a Dutch junk domain on Reddit

\begin{tabular}{|c|c|c|c|c|}
\hline subject & URL & subreddit & timestamp & score \\
\hline $\begin{array}{l}\text { Amsterdam Square driver } \\
\text { (terrorist) before declared } \\
\text { a confused and sick Dutch } \\
\text { national is now revealed } \\
\text { to be KHALID K. from } \\
\text { Casablanca. The media } \\
\text { cover up doesn't stop! }\end{array}$ & $\begin{array}{l}\text { dagelijksestandaard. } \\
\text { nl/2017/08/onthulling- } \\
\text { werkelijke-naam- } \\
\text { van-de-amserdamse- } \\
\text { stationsrammer-blijkt- } \\
\text { dus-khalid-karmaoui/ }\end{array}$ & The_Donald & $\begin{array}{l}22 / 08 / 2017 \\
13: 31\end{array}$ & 1811 \\
\hline $\begin{array}{l}\text { Japan ONLY Admits } 27 \\
\text { Muslim 'Refugees', Two } \\
\text { Already Arrested For Gang } \\
\text { Rape. }\end{array}$ & $\begin{array}{l}\text { fenixx.org/2017/05/14/ } \\
\text { japan-only-admits- } \\
\text { 27-muslim-refugees- } \\
\text { two-already-arrested- } \\
\text { for-gang-rape/ }\end{array}$ & The_Donald & $\begin{array}{l}15 / 05 / 2017 \\
06: 02\end{array}$ & 1211 \\
\hline $\begin{array}{l}\text { Japan ONLY Admits } 27 \\
\text { Muslim 'Refugees', Two } \\
\text { Already Arrested For Gang } \\
\text { Rape. }\end{array}$ & $\begin{array}{l}\text { fenixx.org/2017/05/14/ } \\
\text { japan-only-admits- } \\
\text { 27-muslim-refugees- } \\
\text { two-already-arrested- } \\
\text { for-gang-rape/ }\end{array}$ & CringeAnarchy & $\begin{array}{l}10 / 08 / 2017 \\
5: 13\end{array}$ & 936 \\
\hline
\end{tabular}

Data source: 4CAT and Pushshift. Timeframe: 01-Dec-2015 to 01-Jun-2019 
Figure 6.18 Subreddits where Dutch junk news domains are most often posted

\section{Subreddits $\bullet$ where Dutch junk news appears most often}

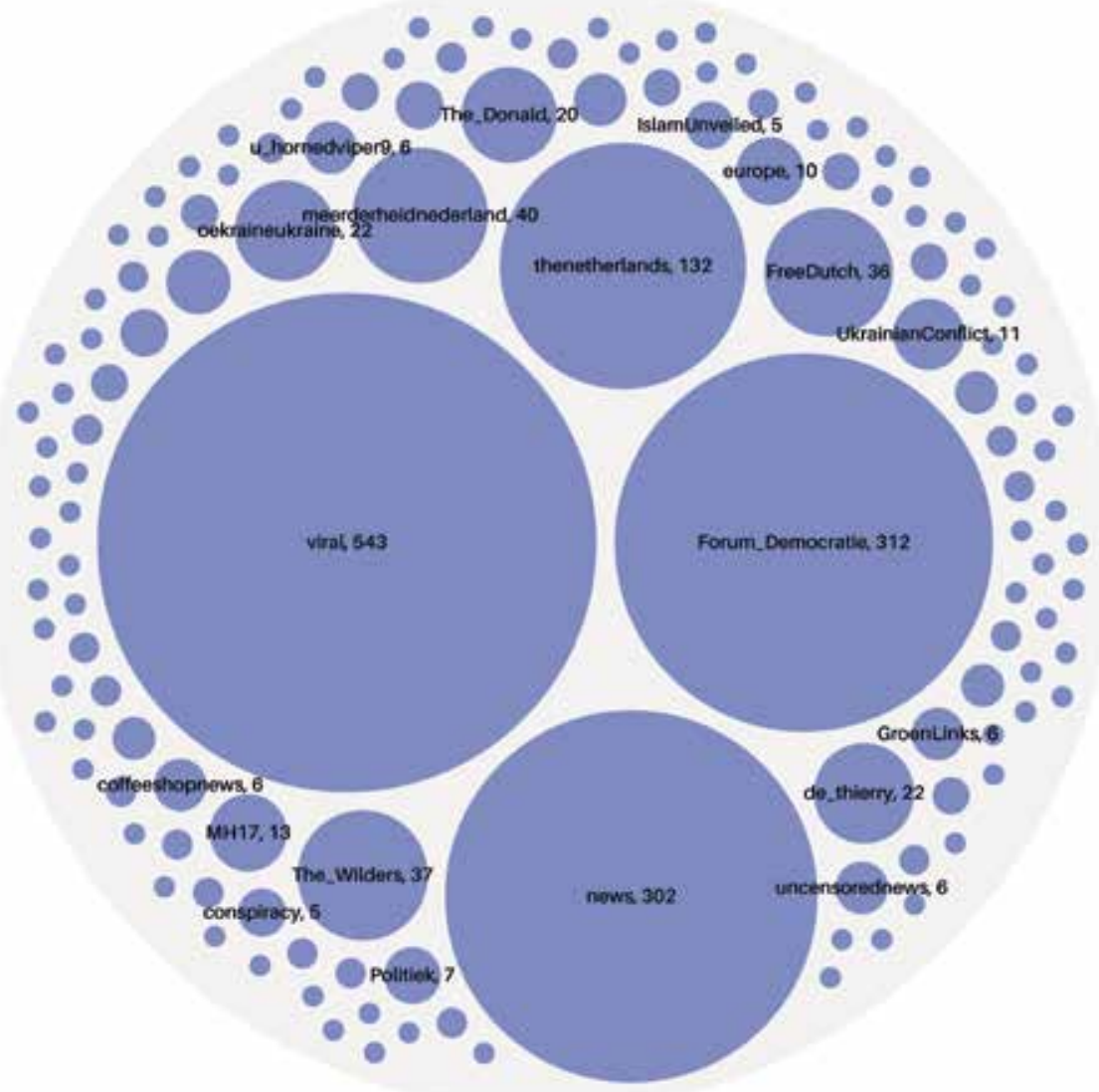

Data source: 4CAT and Pushshift; timeframe: from 1-Dec-2015 to 31-Jun-2019; circle pack diagram

the same story by Fenixx that framed a man who drove a car into a group of people at Amsterdam Central Station as a Moroccan terrorist, even though he was officially declared as unwell and confused. Interestingly, these stories are posted in English-language subreddits, notably the pro-Trump $\mathrm{r} /$ The_Donald and the now-banned $\mathrm{r} /$ CringeAnarchy, showing how junk news from the Netherlands spreads to foreign spaces.

In summary, the overall performance of Dutch junk news throughout Reddit is fairly weak. Moreover, the high-scoring stories are usually hyperpartisan instead of clear-cut disinformation. Dutch junk news thereby can garner considerable engagement on Reddit, but it does not do so on a 
Figure 6.19 Most linked to Junk news domains on all of Reddit

\section{Dutch junk domains • on Reddit}

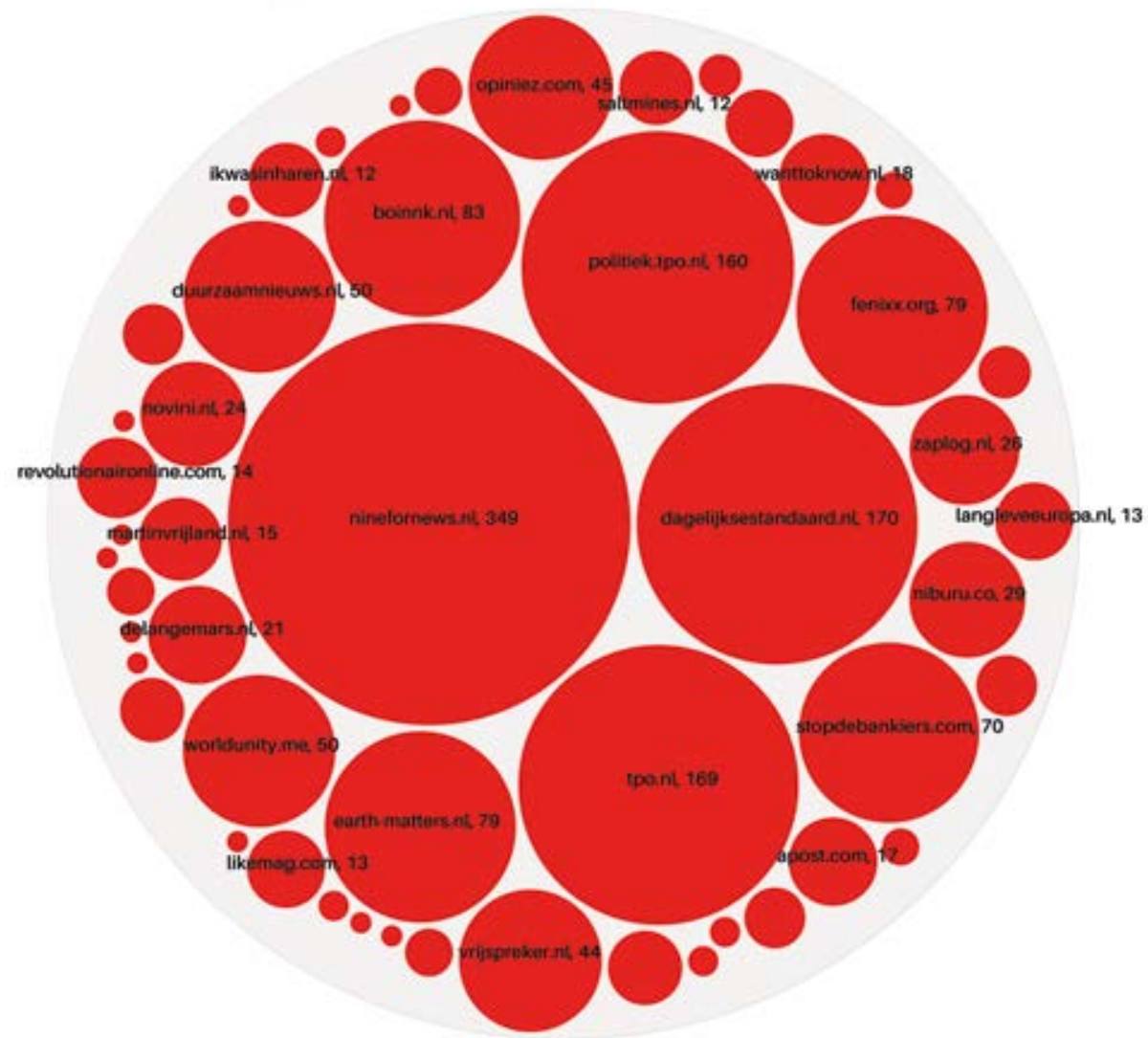

Data source: 4CAT and Pushshift; timeframe: from 1-Dec-2015 to 1-Jun-2019; circle pack diagram

regular basis. In this sense, Reddit is more 'resistant' to junk news than (for example) Facebook is said to be (Burger et al., 2019).

In which subreddits are Dutch junk news domains posted? Figure 6.18 shows that r/viral links to most Dutch junk news with 543 instances, but much of the prevalence is caused by a single 'spam' account, receiving no engagement whatsoever. More interestingly, r/Forum_Democratie, the unofficial subreddit for the currently the largest party in the Dutch Senate, comes in second with 312 posts to junk news sites. Other right-wing partisan and hyperpartisan subreddits appear further down the long tail, such as r/The_Wilders, r/FreeDutch, r/meerderheidnederland, r/The_Donald, and r/de_thierry. This is mainly caused by posts on these subreddits linking to The Post Online and De Dagelijkse Standaard. 


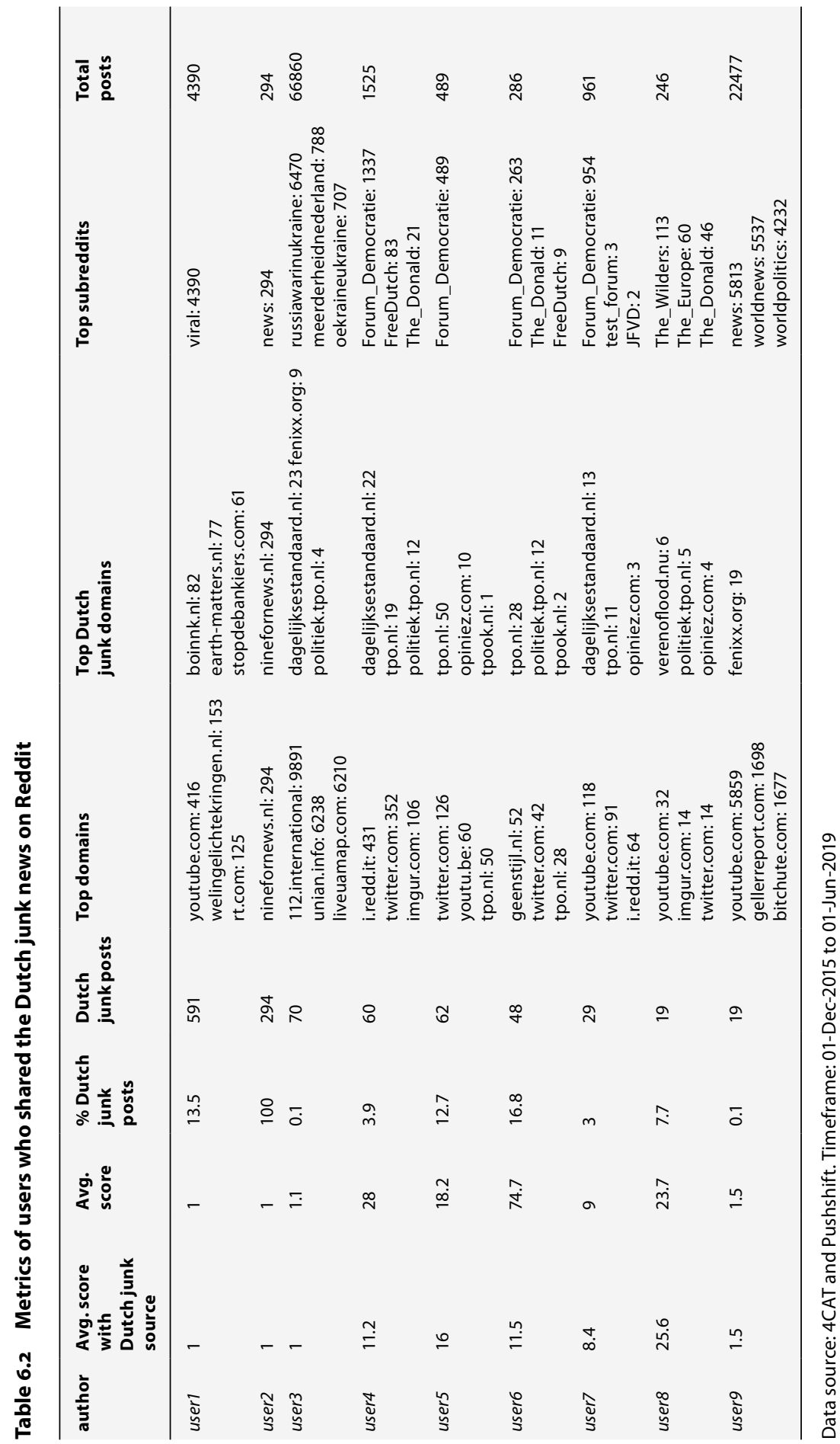


According to Figure 6.19, the junk domains that are linked to often are mostly the well-known right-wing tendentious and hyperpartisan blogs, with The Post Online and De Dagelijkse Standaard ranking on top. The 'alternative' news website NineForNews, which has been host to conspiracies and hyperpartisanship (Roermund, 2017), is also amongst the most shared domains, but this is mostly due to an automated bot posting links to the website (u/ninefornews). As such, most of the shared junk news domains can be categorized as hyperpartisan, often with an 'alternative', right-wing stance. Signs of disinformation or coordinated Russian influence are fairly marginal, with Novini appearing 22 times, a website known for pro-Putin sentiment (Heck, 2017). As such, from this needle to haystack method, partisan and hyperpartisan content is easy to find, but disinformation appears to be less of an issue.

Finally, we highlight the Reddit accounts most active in propagating junk news to profile actor types. Table 6.2 shows various metrics on the ten accounts ranked by the amount of posts linking to one of the domains in the expert list. As indicated by total posts and average score, some of the accounts post frequently but receive no engagement. Most of these are 'spam' accounts or automated bots. Interestingly, user 1 , the aforementioned $u / m r t h i r d e y e 68$, has posted many URLs to Russian and pro-Russian websites as RT.com and novini.nl, as well as mainstream sources and hyperpartisan websites like Red Ice TV. It is possible that user 1 is a Russian 'troll'. It received no upvotes, however, and only posted links to the obscure subreddit $r / v i r a l$, meaning it did not garner any engagement. As such, it is likely this user is an automated bot, or some hybrid. Other bots seem more effective, however. User 2, for instance, is the abovementioned ninefornews.nl bot, posting a hundred percent of posts to this website in the global news subreddit r/news. Of interest here is that user 2 does receive engagement, with a fairly high average post score of 570 and a junk news post score of 50 . As such, Reddit is at least somewhat susceptible to manipulation, depending on the 'strategy' of its users.

In terms of issues, it can be discerned that the most active accounts are either concerned with Dutch right-wing parties or topics surrounding Ukraine. Despite their frequent linking to junk news websites, the most active accounts still link most often to platforms like YouTube and Twitter. ${ }^{12}$ A cohort of four right-wing partisans can be observed, who are most active on r/Forum_Democratie and frequently link to websites like GeenStijl and The Post Online. Most of the accounts actually use the Dutch language, and, upon

12 Further research might scrutinise what YouTube videos or Tweets are linked to, for instance to identify further 'newsy' sources or influencers. 
closer inspection, are also likely Dutch natives. As such we may conclude that there is not a significant attempt of foreign accounts meddling with Dutch affairs, with the possible exception of the now-banned $\mathrm{u} / \mathrm{mrth}$ irdeye68.

\section{YouTube as an alternative news network}

Thus far, this text has handled 'news' in the conventional sense of designated outlets publishing on current affairs. As discussed in the introduction, however, the consumption of both amateur and professional reporting increasingly occurs on social media. These modern, alternative ways of news consumption cannot be identified when the 'needle' is formulated as traditional news outlets. As we have identified in section 3, URLs linking to YouTube are frequent, especially on $4 \mathrm{chan}$. As discussed elsewhere in this volume, the video hosting site is host to various spheres of alternative news commentary and opinions, leading Zeynep Tufekci to describe it as 'the Great Radicalizer' (2018). Can we indeed outline an 'alternative news network' working in tandem with 4chan/pol/and Reddit? This section briefly touches on this question by visualizing and categorizing the most-posted videos on $4 \mathrm{chan} / \mathrm{pol} /$ and Reddit, as well as the most popular channels.

Figures 6.20 and 6.22 display the thumbnails of the 1008 most-posted YouTube videos within our Dutch Reddit and $4 \mathrm{chan} / \mathrm{pol} /$ corpora. Figures 6.21 and 6.23 show the 'video categories' for each of these videos. For the top videos on Dutch subreddits, 161 are concerned with 'People and Blogs', 129 with 'Entertainment', and 118 with 'News \& Politics'. From this, the type of content shared is fairly diverse. $4 \mathrm{chan} / \mathrm{pol} /$ is more concentrated on news and politics, with 196 videos categorized as such, with 'People \& Blogs' following at 95 and 'Entertainment' at 64 .

The number of missing videos for 4 chan (the black labels) is notable, comprising almost half of the total, indicating 4 chan's extremism as well as YouTube content moderation. The number of deleted videos is visibly less on Reddit.

If one takes the videos labelled as 'News \& Politics' as an indicator of a 'news source', as we categorized in the sections above, it becomes possible to quantify the role of YouTube as a news source on the two platforms. The 'News \& Politics' category comprises $11.7 \%$ of the still-online videos for Reddit in the sample above, and $19.4 \%$ for that of $4 \mathrm{chan} / \mathrm{pol} /$. Considering the total amount of links to still-online YouTube videos in this timeframe $-7,667$ for Reddit and 26,635 for $4 \mathrm{chan} / \mathrm{pol} /$ - one can estimate that around 896 'News \& Politics' videos were posted on Dutch subreddits and 3,748 on 4chan/pol/ 
by users with a Dutch flag. ${ }^{13}$ Comparing these numbers to those presented in section 3 , for YouTube news videos would constitute the largest and second largest source of news content. On Reddit, they would form the second-largest news source, only behind NOS.nl with 1,615 mentions. For 4chan, YouTube is by far the largest player in relation to news circulation, since the next most popular source, NOS.nl (861 mentions), comprises only one-third of the amount YouTube news videos. As such, the role of YouTube as a new player in the circulation and consumption of news should not be understated.

Is this dominant presence of YouTube of great significance in the study of junk news? Table 6.3 shows the 25 most-occurring channels from all of the YouTube links in our two Dutch corpora. Here, the platforms differ significantly. On Reddit, some partisan channels can be discerned, like the one for Forum voor Democratie and PVV pers, but the list mostly consists of 'established' sources like NOS, GeenStijl, and VPRO Zondag met Lubach. On 4chan/pol/, however, they are far more extreme and potentially harmful. The most-posted channel is SouthFront, dedicated to videos on the Syrian civil war. Below that is Stefan Molyneux, a popular Canadian YouTuber who promotes 'scientific racism' and white supremacist views. Further down the list are (hyper)partisan news channels like Fox News as well as the Russian RT and Ruptly. Other far-right YouTubers and channels also appear, like Paul Joseph Watson and Rebel Media, as well as some left-leaning channels like The Young Turks and VICE. Together, the channels referred to by Dutch posters are thus of a hyperpartisan, sometimes with a far-right makeup. As such, YouTube videos on Dutch subreddits seem to align with consumption of 'established' and 'traditional' news media outlets, while those on $4 \mathrm{chan} / \mathrm{pol} /$ show a highly hyperpartisan and polarized landscape.

\section{Conclusions}

Despite the frequent characterization of Reddit and 4chan as 'alternative' zones on the Web, the results presented in this text generally do not reveal a large share of alternative news networks spreading disinformation within the platforms, at least in a Dutch context. Despite a few instances of pro-Russian websites like Novini and one suspicious Reddit account, coordinated campaigns of malicious users posting links to disinformation seem largely absent. Dubious content can certainly be discerned but compared to overall activity (as shown in section two) it should be considered fairly marginal within the spaces we

13 In reality, these numbers will be somewhat lower because not every YouTube URL points to videos (they can also refer to channels), although the vast majority in our corpus does. 
Figure 6.20 The top 1008 most posted YouTube videos in Dutch subreddits. Black labels denote deleted videos/channels. Ranked left to right, top to bottom

Reddit - Dutch subreddits Most linked Youtube videcs 1 Dec 2015 - 1 Jun 2019

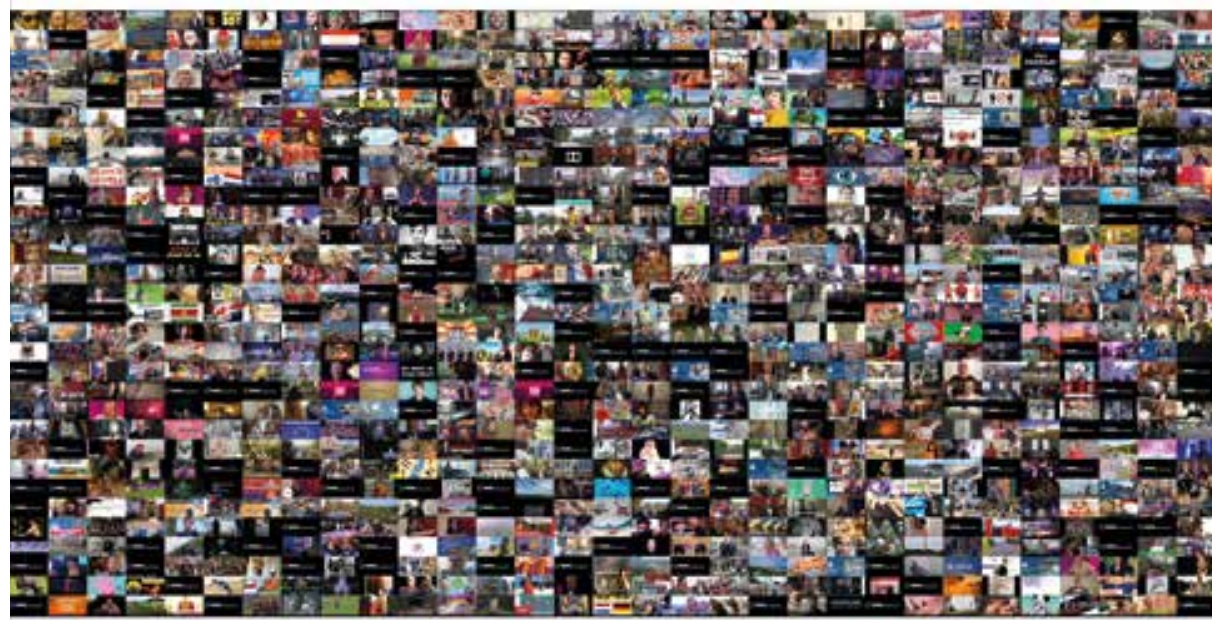

Data source: 4CAT, Pushshift, and YouTube API; image wall

Figure 6.21 The top 1008 most posted YouTube videos in Dutch subreddits, with video categories as an overlay. Black labels denote deleted videos/ channels. Ranked left to right, top to bottom

Reddit - Dutch subreddits Most linked Youtube videos 1 Dec 2015 - 1 Jun 2019

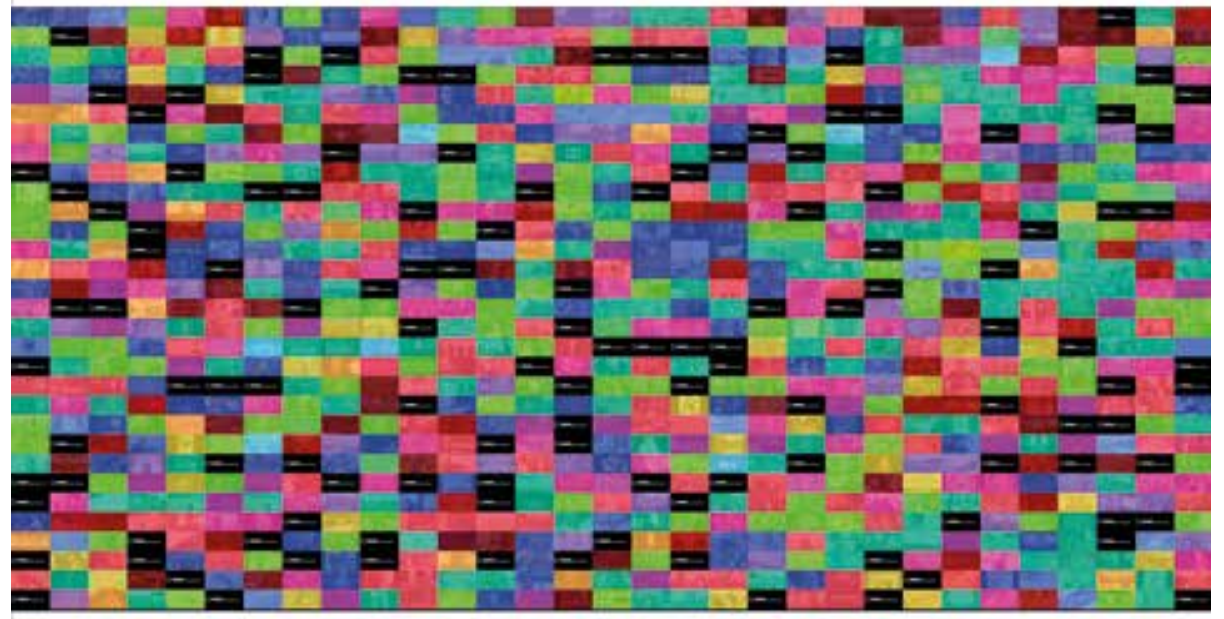

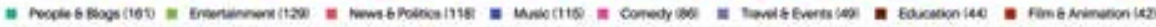

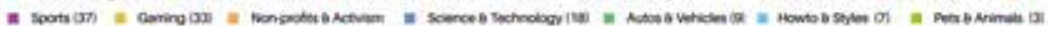

Data source: 4CAT, Pushshift, and YouTube API; image wall 
Figure 6.22 The top 1008 most posted YouTube videos in $4 \mathrm{chan} / \mathrm{pol} /$ in posts with a Dutch country flag. Black labels denote deleted videos/channels. Ranked left to right, top to bottom

4Chan/poV - Dutch country flags Most linked Youtube videcs 1 Dec 2015 - 1 Jun 2019

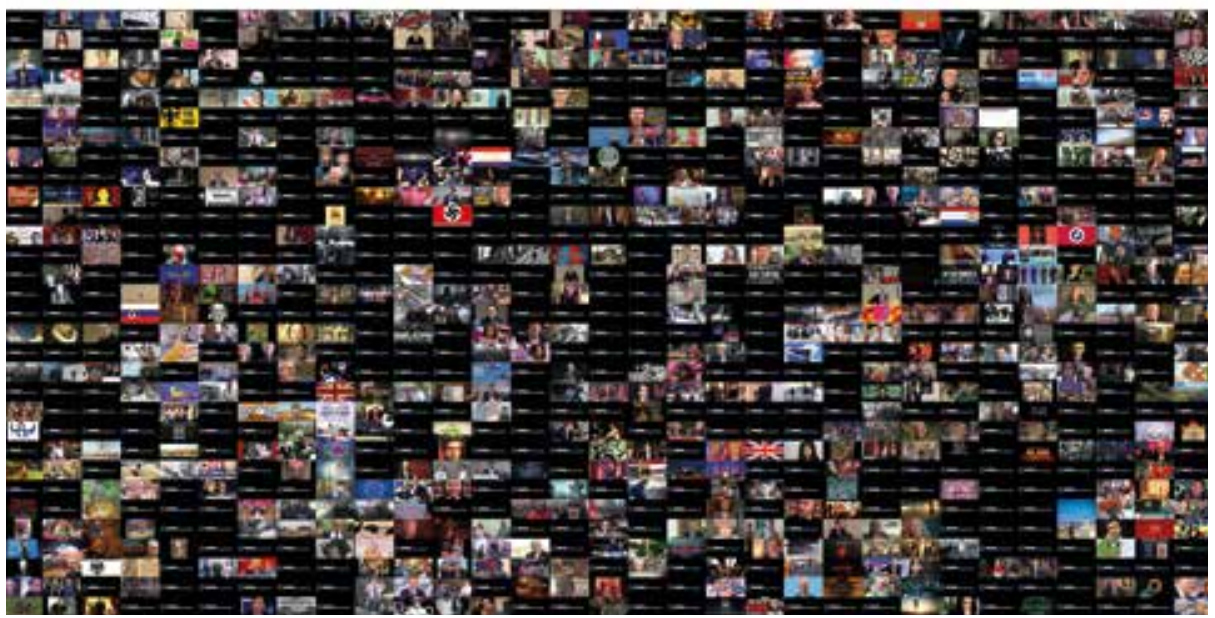

Data source: 4CAT and YouTube API; image wall

Figure 6.23 The top 1008 most posted YouTube videos in 4chan/pol/in posts with a Dutch country flag, with video categories as an overlay. Ranked left to right, top to bottom. Black labels denote deleted videos/channels

4Chan/pol/- Dutch country flags Most linked Youtube videos 1 Dec 2015 - 1 Jun 2019

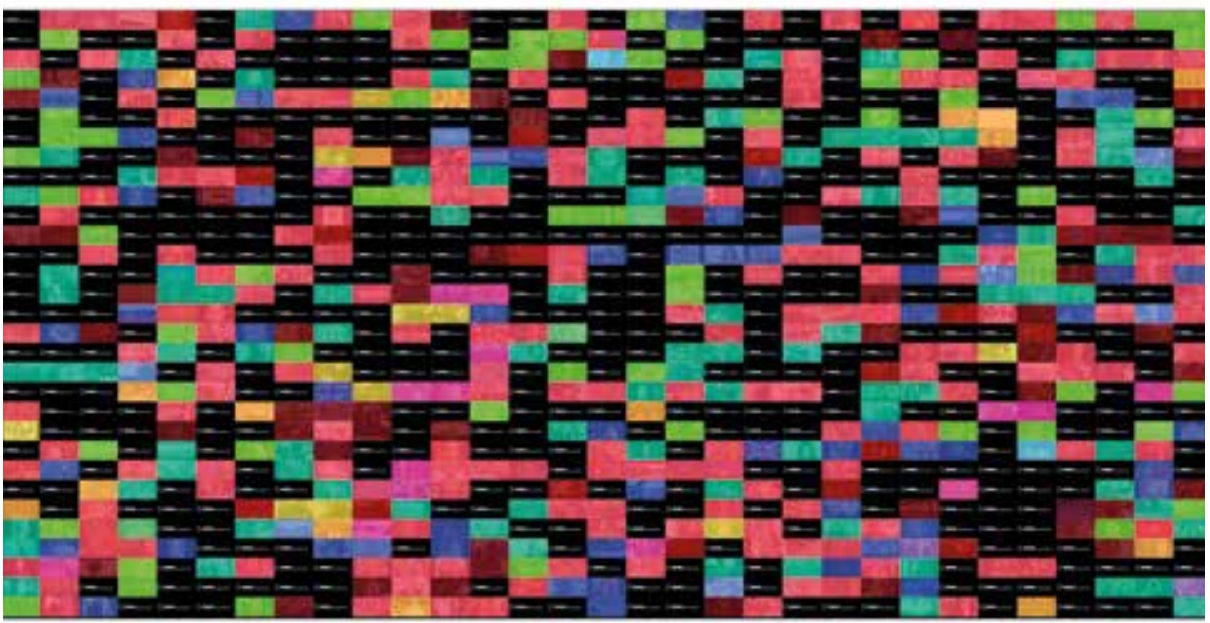

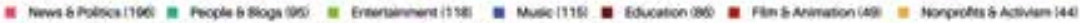

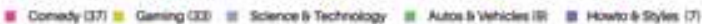

Data source: 4CAT and YouTube API; image wall 
Table 6.3 The most occurring YouTube channels from all YouTube links posted in the Dutch Reddit and 4chan/pol/ samples. Data source: 4CAT, Pushshift, and YouTube API. Timeframe: 01-Dec-2015 to 01-Jun-2019

\begin{tabular}{|c|c|c|c|c|c|c|c|}
\hline \multicolumn{4}{|c|}{$\begin{array}{c}\text { 4chan/pol/ - top } 25 \text { most-occurring } \\
\text { channels }\end{array}$} & \multicolumn{4}{|c|}{$\begin{array}{l}\text { Reddit - top } 25 \text { most-occurring } \\
\text { channels }\end{array}$} \\
\hline channel & count & channel & count & channel & count & channel & count \\
\hline South Front & 191 & $\begin{array}{l}\text { FOX } 10 \\
\text { Phoenix }\end{array}$ & 49 & AFC Ajax & 476 & AT5 & 38 \\
\hline $\begin{array}{l}\text { Stefan } \\
\text { Molyneux }\end{array}$ & 177 & sanderson1611 & 46 & VitesseTV & 269 & FvD Meems & 37 \\
\hline Fox News & 156 & PewDiePie & 41 & $\begin{array}{l}\text { Forum } \\
\text { Democratie }\end{array}$ & 143 & De Speld & 36 \\
\hline$R T$ & 155 & $\begin{array}{l}\text { Paul Joseph } \\
\text { Watson }\end{array}$ & 39 & $\begin{array}{l}\text { Omroep } \\
\text { PowNed }\end{array}$ & 107 & $\begin{array}{l}\text { Football- } \\
\text { Oranje }\end{array}$ & 32 \\
\hline $\begin{array}{l}\text { The White } \\
\text { House }\end{array}$ & 136 & $\begin{array}{l}\text { Acts17Apolo- } \\
\text { getics }\end{array}$ & 38 & $\begin{array}{l}\text { Politie } \\
\text { \#PRO247 }\end{array}$ & 95 & LISSAUER & 31 \\
\hline Ruptly & 125 & Rebel Media & 37 & BRAXATORES & 82 & vpro.nl & 30 \\
\hline $\begin{array}{l}\text { Right Side } \\
\text { Broadcasting } \\
\text { Network }\end{array}$ & 112 & VICE & 37 & $\begin{array}{l}\text { VPRO Zondag } \\
\text { met Lubach }\end{array}$ & 69 & De Telegraaf & 30 \\
\hline $\begin{array}{l}\text { Omroep } \\
\text { PowNed }\end{array}$ & 108 & Fullwhiskey & 36 & GeenStijl & 67 & NOS op 3 & 30 \\
\hline $\begin{array}{l}\text { U.S. } \\
\text { Department } \\
\text { of State }\end{array}$ & 76 & VICE News & 34 & $\begin{array}{l}\text { Cafe } \\
\text { Weltschmerz }\end{array}$ & 51 & Hoop Stront & 29 \\
\hline CNN & 68 & $A B C$ News & 34 & NOS & 51 & PVVpers & 28 \\
\hline $\begin{array}{l}\text { Forum } \\
\text { Democratie }\end{array}$ & 67 & DeroVolk & 33 & $W N L$ & 48 & $R T L Z$ & 27 \\
\hline Fox Business & 65 & corbettreport & 31 & $x b o x$ & 47 & $\begin{array}{l}\text { Politie Den } \\
\text { Haag }\end{array}$ & 24 \\
\hline $\begin{array}{l}\text { The Young } \\
\text { Turks }\end{array}$ & 56 & & & TopNotch & 43 & & \\
\hline
\end{tabular}

scrutinized. Reddit seems especially resilient against the circulation of junk news. In turn, the characterization as actors within 4 chan and parts of Reddit as influential 'agenda setters' should therefore likely be taken with a grain of salt.

What can be observed, however, are the types of junk news that can be characterized as hyperpartisan, especially on $4 \mathrm{chan} / \mathrm{pol} /$. This appeared mostly through links to popular tendentious and hyperpartisan blogs like The Post Online and De Dagelijkse Standaard, but also the more clearly 'fake' (in the sense of conspiratorial) NineForNews. This right-wing bias is expected for $4 \mathrm{chan} / \mathrm{pol} /$ due to its infamy as a far-right hub; for Reddit it is more notable because we took a politically diverse range of URLs and subreddits 
as a starting point. While labelling these websites as 'fake' is problematic, they do indicate a non-negligible presence of polarizing content. Indeed, section four showed that the most engaged-with articles from these websites often concern topics like migration and Islam, instead of other geopolitical events like Russian interference.

Nonetheless, mainstream sources such as NOS.nl remain popular linked-to domains on both Reddit and $4 \mathrm{chan} / \mathrm{pol} /$. This is somewhat counterintuitive since it has been argued the 'fringe' characterization of these pseudonymous and anonymous spaces implies their users find knowledge in different epistemological drawers. Despite these assumptions, the prevalence of mainstream sources shows they have at least some authority within these online spaces. It is important to note, however, that we have not considered how these mainstream websites are discussed. Likely, domains like NOS. $\mathrm{nl}$ are considered on Reddit as a trustworthy source, while on $4 \mathrm{chan} / \mathrm{pol} /$ it might be referenced purely to ridicule it or to portray it as 'fake news' itself - as is discussed elsewhere in this volume.

One should furthermore not be blinded by exclusively considering websites devoted to reporting on current affairs as the sole source of news, as YouTube emerged as a particularly big 'new' player in relation to news consumption and circulation, especially on 4chan/pol/. On Reddit, 'News \& Politics' videos on YouTube are estimated to form the second-largest source, while on $4 \mathrm{chan} / \mathrm{pol} /$, they are estimated to strongly outperform any other news source. From a brief exploration of the YouTube channels posted on both platforms, it seems Dutch Reddit is largely linking to fairly established sources, like PowNed, Zondag met Lubach, and NOS, while on 4chan/pol/, alternative, hyperpartisan, and problematic information channels emerged, like Mike Cernovich and RT. As such, non-Dutch YouTube content might have a 'radicalizing' role on Dutch users within certain Internet forums.

Since this report concerns the news sources linked to by actors on Reddit and 4chan, it does not shed light on the grassroots production of alternative news or conspiracies within these spaces. As Tuters et al. (2018) show in relation to the Pizzagate conspiracy, the wildest theories can be cooked-up in these spaces through a short burst of a 'butterfly effect' of 'bullshit', unobservable when merely considering the prominence of URLs. A more holistic approach, also taking into account text and images, could thus aid in further contextualizing the current 'fake news' debate. Instead of identifying isolated issues of 'fake news', such broader approaches could tackle the interwoven problematics surrounding the circulation of 'junk news' (Venturini, 2019) and 'network propaganda' (Benkler et al., 2018), from the conspiracist mindset of 'viralityoriented subcultures' to the prevalence of polarizing hyperpartisan content. 


\section{References}

Alexander, Julia (2017) 'Reddit's New Policy Won't Affect Some of Its Most Notorious, Hate-Filled Subreddits', Polygon (blog). 2 November. https://www.polygon. com/2017/11/2/16591508/reddit-content-policy-update-subreddit-ban-the-donald-kia.

Baumgartner, Jason (2018) 'Pushshift API (version 1.o)', API Documentation, Pushshift.https://pushshift.io/api-parameters/.

Benkler, Yochai, Robert Faris and Hal Roberts (2018) Network Propaganda:Manipulation, Disinformation, and Radicalization in American Politics, Oxford: Oxford University Press.

Bos, Menno van den (2018) 'Nee, Jíj Bent Een Cultuurrelativist! Hoe Academische Begrippen Strijdwapens Werden', Vrij Nederland, 12 December. https://www. vn.nl/identiteitspolitiek-cultuurmarxisme-intersectionaliteit/.

Burger, Peter (2016) 'Moslims vernielen kerstmarkt in Litouwen? Nee: rellen in de VS', De Gestolen Grootmoeder blog (blog), 14 December. http://www.gestolengrootmoeder.nl/wordpress/moslims-vernielen-kerstmarkt-in-litouwen-nee-rellen-in-de-vs/.

Collins, Ben and John Russell (2018) 'Russians Used Reddit and Tumblr to Troll the 2016 Election', The Daily Beast, 2 March. https://www.thedailybeast.com/ russians-used-reddit-and-tumblr-to-troll-the-2016-election.

De Hoax-Wijzer (n.d.) 'Valse Nieuwssites'. https:/sites.google.com/site/dehoaxwijzer/ valse-nieuwssites.

Dupuy, Lisa (2018) 'GeenStijl Staat Niet Meer Op EU-Lijst Nepnieuws', NRC Handelsblad, 29January. https://www.nrc.nl/nieuws/2018/o1/29/geenstijl-staat-nietmeer-op-eu-lijst-nepnieuws-a1590216.

EU vs Disinfo. 2017. 'Sputnik's Short-Lived Presence in the Slovak Press Agency', EU vs Disinfo (blog), , April. https://euvsdisinfo.eu/sputniks-short-lived-presencein-the-slovak-press-agency/.

Hagen, Sal, Daniël de Zeeuw, Stijn Peeters, Emilija Jokubauskaitė and Ángeles Briones (2019). 'Understanding Normiefication: A Cross-Platform Analysis of the QAnon Conspiracy Theory', Digital Methods Initiative, 21 February.https:// wiki.digitalmethods.net/Dmi/WinterSchool2019Normiefication.

Hankes, Keegan and Alex Amend (2018) 'The Alt-Right Is Killing People', Southern Poverty Law Center, 5 February. https://www.splcenter.org/20180205/ alt-right-killing-people.

Heck, Wilmer (2017) 'Rusland Beïnvloedt Ons Vooral Online', NRC Handelsblad, 8 January.

Helmond, Anne (2015) 'The Platformization of the Web: Making Web Data Platform Ready', Social Media + Society 1(2):1-11. https://doi.org/10.1177/2056305115603080. Herrman, John (2016) 'Inside Facebook's (Totally Insane, Unintentionally Gigantic, Hyperpartisan) Political-Media Machine', The New York Times, 28 August. https:// 
www.nytimes.com/2016/o8/28/magazine/inside-facebooks-totally-insaneunintentionally-gigantic-hyperpartisan-political-media-machine.html.

Herrman, John (2016) 'Inside Facebook’s (Totally Insane, Unintentionally Gigantic, Hyperpartisan) Political-Media Machine', The New York Times, 28 August. https:// www.nytimes.com/2016/08/28/magazine/inside-facebooks-totally-insaneunintentionally-gigantic-hyperpartisan-political-media-machine.html.

Huet, Bob van (2018) 'QAnon Rukt Op in Amerika: Complotgekkies of Wakkere Patriotten?' Algemeen Dagblad, 3 August. https:/www.ad.nl/buitenland/ qanon-rukt-op-in-amerika-complotgekkies-of-wakkere-patriotten aa24a2ab/.

Kranenberg, Annieke and Hassan Bahara (2018) 'Hoe alt-right online Jodenhaat verspreidt', de Volkskrant, 9 November. https://www.volkskrant.nl/gs-b1714693.

Lagorio-Chafkin, Christine (2018) 'Reddit Confirms New Russian Meddling Efforts', Inc., 4 October.https://www.inc.com/christine-lagorio/reddit-finds-new-russianinterference-campaign.html.

MacFarquhar, Neil (2018) 'A Powerful Russian Weapon: The Spread of False Stories', The New York Times, 20 January. https:/www.nytimes.com/2016/o8/29/world/ europe/russia-sweden-disinformation.html.

Marwick, Alice and Rebecca Lewis (2017) 'Media Manipulation and Disinformation Online', Data \& Society, New York.

Mauri, Michele, Tommaso Elli, Giorgio Caviglia, Giorgio Uboldi and Matteo Azzi (2017) 'RAWGraphs: A Visualisation Platform to Create Open Outputs', in Proceedings of the 12th Biannual Conference on Italian SIGCHI Chapter, 28:1-28:5. CHItaly '17, New York, NY: ACM.https://doi.org/10.1145/3125571.3125585.

Muirhead, Russell and Nancy L. Rosenblum (2019) A Lot of People Are Saying: The New Conspiracism and the Assault on Democracy, Princeton, NJ: Princeton University Press.

Oudenampsen, Merijn (2013) 'Met de Tjoeki Tjoeki Naar Takki Takki'. De Groene Amsterdammer, 3 July. https://www.groene.nl/artikel/met-de-tjoeki-tjoekinaar-takki-takki.

Peek, Simone (2018) 'NOS-Hoofdredacteur Over Bericht Soros: "Zo Had Het Niet Gemoeten"', NRC Handelsblad, 24 October.

Phillips, Whitney (2018) 'The Oxygen of Amplification: Better Practices for Reporting on Extremists, Antagonists and Manipulators Online', Data \& Society, New York. Roermund, Jannes van (2017) 'Wie Zijn de Mensen Achter Het Nepnieuws in Nederland?' Nieuwe Revu, 26 April.

Roig-Franzia, Manuel (2019) 'Inside the Spectacular Fall of the Granddaddy of RightWing Conspiracy Sites', The Washington Post, 2 April. https://www.washingtonpost. com/lifestyle/style/inside-the-spectacular-fall-of-the-granddaddy-of-right-wingconspiracy-sites/2019/04/02/6ac53122-3ba6-11e9-ao6c-3ec8ed509d15_story.html.

Rogers, Richard (2013) Digital Methods, Cambridge, MA: MIT Press 
RTL Nieuws (2018) 'Alles Over Complottheorie QAnon - \#TrumpUpdate 77', RTL Nieuws, 15 September. https://www.rtlnieuws.nl/nieuws/laatste-videos-nieuws/ video/4417801/alles-over-complottheorie-qanon-trumpupdate-77.

Shieber, Jason (2017) 'How Reports from 4chan on the Las Vegas Shooting Showed Up on Google Top Stories', TechCrunch (blog), 2 October. http:// social.techcrunch.com/2017/10/02/how-reports-from-4chan-on-the-las -vegas-shooting-showed-up-on-google-top-stories.

Southern Poverty Law Center (n.d.), 'WorldNetDaily', Southern Poverty Law Center (blog). https://www.splcenter.org/fighting-hate/extremist-files/group/ worldnetdaily.

Thomas, David R. (n.d.) 'A General Inductive Approach for Analyzing Qualitative Evaluation Data', American Journal of Evaluation 27 (2): 238-46. https://doi. org/10.1177/1098214005283748.

Tufekci, Zeynep (2018) 'YouTube, the Great Radicalizer', The New York Times, 10 March. https://www.nytimes.com/2018/03/10/opinion/sunday/youtubepolitics-radical.html.

Tuters, Marc, and Daniël De Zeeuw (2019) 'Teh Internet Is Serious Business: On the Deep Vernacular Web Imaginary', ANSOC Working Paper.

Tuters, Marc, Emilija Jokubauskaitè and Daniel Bach (2018) 'Post-Truth Protest: How 4chan Cooked Up the Pizzagate Bullshit', M/C Journal 21(3). http://journal. media-culture.org.au/index.php/mcjournal/article/view/1422.

Venturini, Tommaso (2019) 'From Fake to Junk News, the Data Politics of Online Virality', in Didier Bigo, Engin Isin, and Evelyn Ruppert (eds), Data Politics: Worlds, Subjects, Rights. London: Routledge. https://hal.archives-ouvertes.fr/ hal-02003893.

Wendling, Mike (2018). Alt-Right:From 4chan to the White House. London: Pluto Press. Zannettou, Savvas, Tristan Caulfield, Emiliano De Cristofaro, Nicolas Kourtelris, Ilias Leontiadis, Michael Sirivianos, Gianluca Stringhini and Jeremy Blackburn (2017) 'The Web Centipede: Understanding How Web Communities Influence Each Other through the Lens of Mainstream and Alternative News Sources', 17th ACM Internet Measurement Conference, 405-17.

\section{About the authors}

SAl HAgEN is a Ph.D. candidate at the University of Amsterdam and cofounder of OILab. His research focuses on anonymous and pseudonymous online subcultures and their political engagements. Methodologically, his work combines media theory with data-driven methods. 
Emilija Jokubauskaité is a Ph.D. candidate and lecturer in Media Studies at the University of Amsterdam as well as co-founder of the Open Intelligence Lab. Her main research interests consist of fringe online spaces and platforms as well as the scrutiny of research tools and techniques.

\section{Appendices}

\section{Appendix 6.1 Compiled list of Dutch Subreddits}

\section{Table 6.4 Compiled list of Dutch subreddits}

ADODenHaag,AjaxAmsterdam,Alkmaar,Aluhoedjes,Amersfoort,Amsterdam,AmsterdamE nts,Appiememes,Arnhem,Aruba,Assen,avd,AZAlkmaar,Bassie_en_Adriaan,BeermoneyNL ,BeNeLux,Bier,Binnenhof,BitcoinNL,Boeken,Bonaire,BuurmanEnBuurman,CariceVanHoute n,CelebsNL,Cirkeltrek,CreatieveKoppen,Curacao,de_thierry,de_thierry,DeCorrespondent, DeGraafschap,Delain,Delft,Depressie,DeSpeldOfNietDeSpeld,DeStaat,DeStagiair,DeTand enborstel,DirkJan,Dordrecht,DoucheGedachten,DoutzenKroes,Drenthe,Duindorp,Dumo ulin,Dunglish,dutch,Dutch,DutchBoardgames,DutchComedy,DutchDesign,DutchEnts,Du tchFIRE,DutchHipHop,DutchHouse,DutchKeto,DutchMusic,DutchPoetry,DutchProblems, DutchSkincare,DutchTech,Eindhoven,Elfstedentocht,Enschede,Epica,Eredivisie,Ethtrader nl,FCGroningen,FCTwente,FCUtrecht,Feyenoord,Formule1,Forum_Democratie,FreeDutch ,Frisia,Frysk,GekkeJongens,Geldzaken,Geschiedenis,Gezellig,Glitterplaatjes,groenlinks,Gr oningen,Haarlem,HanzeMemes,HeilzameMeems,Hulpdiensten,ik_ihe,JuridischAdvies,Ka merstukken,KatholiekeNederlanden,Kibbeling,KNVB,Koffie,Kut_Doen_Op_Tinder,Kutleve n,Kutreclames,LearnDutch,LeCutInsideMan,Leiden,Leraren,LimburgMan,Lowlands,Maast richt,MamaAppelsap,Marktplaats,MaxV,Medejongeren,meerderheidnederland,Metal_NL ,Motorfietsen,NACBreda,NEC,Nedercringe,Nederporn,NepParlement, netherlands,Neth erlandsPics,NietDeSpeld,Nijmegen,NLvsFI,Nuenen,NuJijInActie,oekraineukraine,ossem ,otonde,Papgrappen,ParadoxPlaats,PECZwolle,PodcastNed,PokemonGoNL,Poldersocia lisme,Politiek,Politiekmemes,PSV,RijmenDichten,RMTK,RodaJC,RomeeStrijd,Rotterdam ,Saba,SCCambuur,SCHeerenveen,ScoutsNL,SportNL,Spyker,StefanieJoosten,Strips,Stro opwafels,StudyInTheNetherlands,SXM,SylvieMeis,Tenenkrommend,The_Klaver,The_Wi Iders,TheHague,theNetherlands,theNetherlandsFree,theNetherlandsNature,Tiesto,tokk iefeesboek,tokkiefeesboek,TokkieFeesboek,Top2000,TUDelft,TuurlijklsDatEenDing,Twe nte,Utrecht,VeganNL,Veluwe,VitesseArnhem,Voetbalnieuws,VraagDerNederlanden,Vra agHetAanTonyQuark,Wetenschap,WIDM,WithinTemptation,XboxNederland,Zitkamer,Z onderContext,Zwolle 


\section{Appendix 6.2 Expert List of Dutch Junk News Domains}

Table 6.5 Junk news categorization. Edited and enhanced list originating from Hoax-Wijzer. 23 March, 2019

\begin{tabular}{|c|c|c|}
\hline name & domain_name & category \\
\hline Opiniez & opiniez.com & hyperpartisan \\
\hline Stop de Bankiers & stopdebankiers.com & hyperpartisan \\
\hline t Pallieterke & pallieterke.net & hyperpartisan \\
\hline E.J. Bron & ejbron.wordpress.com & hyperpartisan \\
\hline Dagelijkse Standaard & dagelijksestandaard.nl & hyperpartisan \\
\hline Climategate & climategate.nl & hyperpartisan \\
\hline De Staat van het klimaat & destaatvanhet-klimaat.nl & hyperpartisan \\
\hline JDreport.com & jdreport.com & hyperpartisan \\
\hline tpook.nl & tpook.nl & clickbait \\
\hline Nine for news & ninefornews.nl & conspiracy \\
\hline Daily Paper & dailypaper.org & hyperpartisan \\
\hline Parra & parra.nu & clickbait \\
\hline Viraaltjes & viraaltjes.nl & clickbait \\
\hline about media & aboutmedia.nl & clickbait \\
\hline Martin Vrijland & martinvrijland.nl & conspiracy \\
\hline The Loyalist & loyalist.nl & conspiracy \\
\hline desportgek & desportgek.nl & clickbait \\
\hline Even Delen & evendelen.net & clickbait \\
\hline nietbarkie.nl & nietbarkie.nl & clickbait \\
\hline hardewaarheid.nl & hardewaarheid.nl & clickbait \\
\hline The Post Online & tpo.nl & $\begin{array}{l}\text { tendentious- } \\
\text { hyperpartisan }\end{array}$ \\
\hline Saltmines.nl & saltmines.nl & hyperpartisan \\
\hline eunmask.wordpress.com & eunmask.wordpress.com & hyperpartisan \\
\hline novini.nl & novini.nl & hyperpartisan \\
\hline niburu.nl & niburu.nl & conspiracy \\
\hline React nieuws & reactnieuws.net & hyperpartisan \\
\hline DMLplus & dlmplus.nl & conspiracy \\
\hline martinvrijland.nl & martinvrijland.nl & conspiracy \\
\hline world unity & worldunity.me & conspiracy \\
\hline cultuur onder vuur & cultuurondervuur.nu & hyperpartisan \\
\hline volks nieuws uit Amsterdam noir & volksnieuwsuitamsterdamnoir.com & conspiracy \\
\hline stop pas familie drama & stoppasfamiliedrama.blogspot.com & conspiracy \\
\hline Obed Brinkman & obedbrinkman.noblogs.org & hyperpartisan \\
\hline veren of lood & verenoflood.nu & hyperpartisan \\
\hline De fouten van Rutte & defoutenvanvvdrutte.nl & hyperpartisan \\
\hline Finding voices & finding-voices.blogspot.com & conspiracy \\
\hline ik was in haren & ikwasinharen.nl & hyperpartisan \\
\hline
\end{tabular}




\begin{tabular}{|c|c|c|}
\hline name & domain_name & category \\
\hline Piet Kei & pietkei.nl & conspiracy \\
\hline bewiseman & bewiseman.nl & hyperpartisan \\
\hline Alternatieve Media Nederland & alternatievemedianederland.com & hyperpartisan \\
\hline Apokalypsnu & apokalypsnu.nl & conspiracy \\
\hline Don Quijotte & donquijotte.wordpress.com & conspiracy \\
\hline Drimble & drimble.nl & hyperpartisan \\
\hline Fenixx & fenixx.org & hyperpartisan \\
\hline Hector Reban & hectorreban.wordpress.com & hyperpartisan \\
\hline Herstelde Republiek & herstelderepubliek.wordpress.com & hyperpartisan \\
\hline Kremlin Troll & kremlintroll.nl & hyperpartisan \\
\hline Magilando & magilando.wordpress.com & conspiracy \\
\hline Niburu & niburu.co & conspiracy \\
\hline Absolute Duality & nl.absoluteduality.com & conspiracy \\
\hline Stan van Houcke & stanvanhoucke.blogspot.com & hyperpartisan \\
\hline Stelling & stelling.nl & conspiracy \\
\hline Tref & tref.eu & hyperpartisan \\
\hline Want to know & wanttoknow.nl & conspiracy \\
\hline Xandernieuws & xandernieuws.punt.nl & hyperpartisan \\
\hline APost & apost.com & clickbait \\
\hline Best Gezond & bestgezond.nl & clickbait \\
\hline Bewust Nieuws & bewustnieuws.nl & conspiracy \\
\hline Blik Op NOSjournaal & blikopnosjournaal.blogspot.nl & hyperpartisan \\
\hline Bovendien & bovendien.com & conspiracy \\
\hline Brekend Nieuws & brekendnieuws.nl & conspiracy \\
\hline Dagelijks.nu & dagelijks.nu & clickbait \\
\hline Dagelijkse Krant & dagelijksekrant.nl & clickbait \\
\hline De Stille Waarheid & destillewaarheid.nl & hyperpartisan \\
\hline Earth Matters & earth-matters.nl & conspiracy \\
\hline Ella'ster & ellaster.nl & conspiracy \\
\hline Health Bytes & healthbytes.me & conspiracy \\
\hline $\begin{array}{l}\text { Healthwatch } \\
\text { gezondheidswaakhond }\end{array}$ & healthwatch.nu & conspiracy \\
\hline Leeshetnu & leeshetnu.nl & clickbait \\
\hline Lekkerwonen & lekkerwonen.org & clickbait \\
\hline LikeMag & likemag.com & clickbait \\
\hline Lijstverse & lijstverse.nl & clickbait \\
\hline Live kijken & livekijken.nl & clickbait \\
\hline Nieuwsdump & nieuws-dump.nl & clickbait \\
\hline Not100 & not100.nl & clickbait \\
\hline Ongelooflijke Verhalen & smullen-maar.nl & clickbait \\
\hline Prankster & prankster.nl & clickbait \\
\hline Revolutionair Online & revolutionaironline.com & hyperpartisan \\
\hline Snuggerd & snuggerd.nl & clickbait \\
\hline Time 2 Wake Up & time2wakeup.me & hyperpartisan \\
\hline
\end{tabular}




\begin{tabular}{lll}
\hline name & domain_name & category \\
\hline Tips \& Weetjes & tipsenweetjes.nl & clickbait \\
Tis Wat & tis-wat.nl & clickbait \\
TrendBuzz & trendbuzz.nl & clickbait \\
Trendnieuws & trendnieuws.nl & clickbait \\
Trendnova & trendnova.nl & clickbait \\
United-Lightworkers & united-lightworkers.be & conspiracy \\
Vaccinatieraad & vaccinatieraad.nl & conspiracy \\
Viraalpunt & viraalpunt.nl & clickbait \\
Viral Mundo & viralmundo.nl & clickbait \\
Viraaltje & Viraaltje.nl & clickbait \\
Vrouwen Dingen & vrouwendingen.com & clickbait \\
Vrijspreker & vrijspreker.nl & hyperpartisan \\
The Post Online - Politiek & politiek.tpo.nl & tendentious- \\
Erkenbrand & & hyperpartisan \\
Das Kapital & erkenbrand.eu & hyperpartisan \\
Glop & daskapital.nl & hyperpartisan \\
\hline
\end{tabular}

Appendix 6.3 Metrics on domains shared on Reddit and 4chan/pol/

Table 6.6 Metrics for the proportions of news, Dutch news, Dutch junk news, and categories in posts on Dutch language subreddits, 01-Dec-2015 to 01-Jun-2019

\begin{tabular}{lllllcc}
\hline \multicolumn{2}{c}{$\begin{array}{c}\text { Reddit } \\
\text { 01-12-2015 to 01-06-2019 }\end{array}$} & \multicolumn{2}{c}{ OPs } & Category & Count & Percentage \\
\hline & Positive & Negative & Percentage & Mainstream & 5255 & $89.9 \%$ \\
News & 5959 & 27594 & $21.64 \%$ & Other & 580 & $9.7 \%$ \\
Dutch news & 5557 & 402 & $93.3 \%$ & Hyperpartisan & 24 & $0.4 \%$ \\
Dutch junk news & 24 & 5935 & $0.4 \%$ & Disinformation & 0 & $0 \%$ \\
& & & & Clickbait & 0 & $0 \%$ \\
& & & & Conspiracy & 0 & $0 \%$ \\
\hline
\end{tabular}


Table 6.7 Metrics for the proportions of news, Dutch news, Dutch junk news, and categories in posts on 4chan/pol/ with a country flag from the Netherlands, 01-Dec-2015 to 01-Jun-2019

\begin{tabular}{|c|c|c|c|c|c|c|}
\hline \multicolumn{2}{|c|}{$\begin{array}{c}\text { Reddit } \\
\text { 01-12-2015 to 01-06-2019 }\end{array}$} & \multicolumn{2}{|c|}{ OPs } & \multirow{2}{*}{$\begin{array}{l}\text { Category } \\
\text { Mainstream }\end{array}$} & \multirow{2}{*}{$\frac{\text { Count }}{10399}$} & \multirow{2}{*}{$\begin{array}{c}\text { Percentage } \\
71.5 \%\end{array}$} \\
\hline & Positive & Negative & Percentage & & & \\
\hline News & 14541 & 87301 & $16.6 \%$ & Other & 1414 & $9.5 \%$ \\
\hline Dutch news & 3403 & 11138 & $23.41 \%$ & Hyperpartisan & 2091 & $14.4 \%$ \\
\hline \multirow[t]{3}{*}{ Dutch junk news } & 2809 & 11732 & $19.3 \%$ & Disinformation & 241 & $1.7 \%$ \\
\hline & & & & Clickbait & 45 & $0.3 \%$ \\
\hline & & & & Conspiracy & 351 & $2.4 \%$ \\
\hline
\end{tabular}

Appendix 6.4 Most-posted URLs from posts containing links to RT.com and Sputnik on $4 \mathrm{chan} / \mathrm{pol} /$

Table 6.8 Most occurring URLs from posts containing links to RT.com and Sputnik by posts with a Dutch country flag on $4 \mathrm{chan} / \mathrm{pol} /$. Derived with $4 \mathrm{CAT}$

\begin{tabular}{llc}
\hline Title & URL & $\begin{array}{l}\text { Amount of } \\
\text { appearances }\end{array}$ \\
\hline $\begin{array}{l}\text { Stabbing death of 15yo schoolboy by } \\
\text { 'Arab migrant' classmate in Sweden } \\
\text { sparks outrage }\end{array}$ & $\begin{array}{l}\text { https://www.rt.com/news/329243- } \\
\text { sweden: Rape Capital of the West }\end{array}$ & $\begin{array}{l}\text { https://www.gatestoneinstitute. } \\
\text { org/5195/sweden-rape }\end{array}$ \\
$\begin{array}{l}\text { Sweden charges 5 teenage refugees } \\
\text { hith beating, gang-raping boy for } \\
\text { over an hour }\end{array}$ & $\begin{array}{l}\text { sweden-refugees-rape-afgan-boy/ } \\
\begin{array}{l}\text { Belgian prosecutor's office denies } \\
\text { terrorist track in murder of guard at } \\
\text { nuclear centre }\end{array}\end{array}$ & $\begin{array}{l}\text { https://www.rt.com/news/337276- } \\
\text { belgium-nuclear-guard-killed/ }\end{array}$ \\
$\begin{array}{l}\text { Sex Slave Found Chained in Base- } \\
\text { ment of Immigrant Cafe in Sweden }\end{array}$ & $\begin{array}{l}\text { http://speisa.com/modules/articles/ } \\
\text { index.php/item.3584/sex-slave- } \\
\text { found-chained-in-basement-of- }\end{array}$ & 8 \\
& $\begin{array}{l}\text { immigrant-cafe-in-sweden.html } \\
\text { (now offline) }\end{array}$ & \\
\hline
\end{tabular}


